\title{
Mapping and validation of quantitative trait loci associated with concentrations of 16 elements in unmilled rice grain
}

\author{
Min Zhang • Shannon R. M. Pinson · Lee Tarpley $\cdot$ \\ Xin-Yuan Huang $\cdot$ Brett Lahner $\cdot$ Elena Yakubova $\cdot$ \\ Ivan Baxter $\cdot$ Mary Lou Guerinot $\cdot$ David E. Salt
}

Received: 3 June 2013 / Accepted: 3 October 2013 / Published online: 15 November 2013

(C) The Author(s) 2013. This article is published with open access at Springerlink.com

\begin{abstract}
Key Message QTLs controlling the concentrations elements in rice grain were identified in two mapping populations. The QTLs were clustered such that most genomic regions were associated with more than one element.

Abstract In this study, quantitative trait loci (QTLs) affecting the concentrations of 16 elements in whole, unmilled rice (Oryza sativa L.) grain were identified. Two rice mapping populations, the 'Lemont' $\times$ 'TeQing' recombinant inbred lines (LT-RILs), and the TeQing-intoLemont backcross introgression lines (TILs) were used. To
\end{abstract}

Communicated by T. H. Tai.

Electronic supplementary material The online version of this article (doi:10.1007/s00122-013-2207-5) contains supplementary material, which is available to authorized users.

\section{Zhang}

Department of Statistics, Purdue University, 150 N. University

Street, West Lafayette, IN 47907-2067, USA

e-mail: minzhang@purdue.edu

\section{S. R. M. Pinson $(\bowtie)$}

USDA-ARS, Dale Bumpers National Rice Research Center, 2890

Highway 130 East, Stuttgart, AR 72160, USA

e-mail: Shannon.pinson@ars.usda.gov

\section{Tarpley}

Texas A\&M AgriLife Research, Texas A\&M University System,

1509 Aggie Dr., Beaumont, TX 77713, USA

e-mail: 1tarpley@tamu.edu

X.-Y. Huang · D. E. Salt $(\bowtie)$

School of Biological Sciences, University of Aberdeen, Cruickshank Building, St Machar Drive, Aberdeen, Scotland AB24 3UU, UK

e-mail: david.salt@abdn.ac.uk increase opportunity to detect and characterize QTLs, the TILs were grown under two contrasting field conditions, flooded and irrigated-but-unflooded. Correlations between the individual elements and between each element with grain shape, plant height, and time of heading were also studied. Transgressive segregation was observed among the LT-RILs for all elements. The 134 QTLs identified as associated with the grain concentrations of individual elements were found clustered into 39 genomic regions, 34 of which were found associated with grain element concentration in more than one population and/or flooding treatment. More QTLs were found significant among flooded TILs (92) than among unflooded TILs (47) or among flooded LT-RILs (40). Twenty-seven of the 40 QTLs identified among the LT-RILs were associated with the same element among the TILs. At least one QTL per element was validated in two or more population/environments. Nearly all of the grain

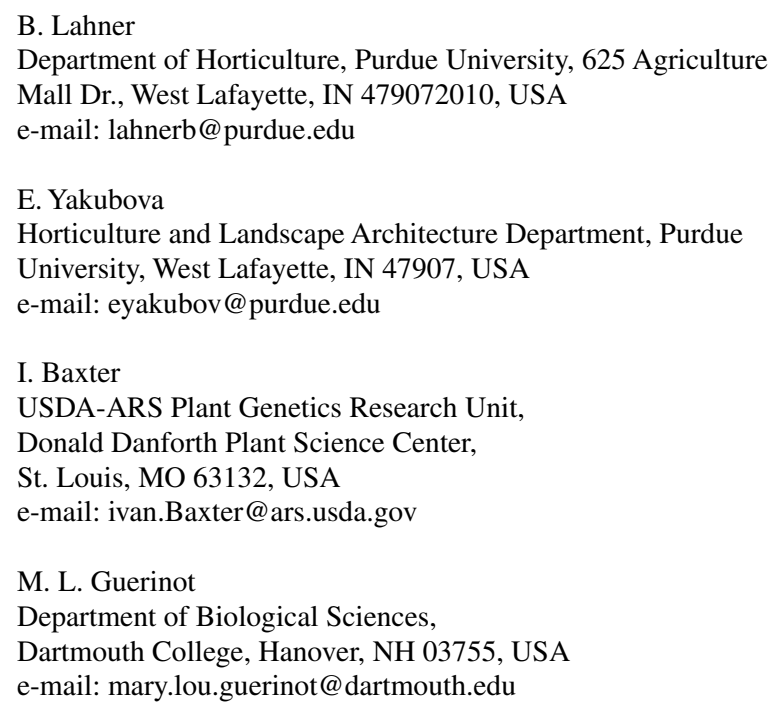


element loci were linked to QTLs affecting additional elements, supporting the concept of element networks within plants. Several of the grain element QTLs co-located with QTLs for grain shape, plant height, and days to heading; but did not always differ for grain elemental concentration as predicted by those traits alone. A number of interesting patterns were found, including a strong $\mathrm{Mg}-\mathrm{P}-\mathrm{K}$ complex.

\begin{tabular}{|c|c|}
\hline \multicolumn{2}{|c|}{ Abbreviations } \\
\hline BIC & Bayesian information criterion \\
\hline $\mathrm{cM}$ & Centimorgans \\
\hline CIM & Composite interval mapping \\
\hline CSSL & Chromosome segment substitution line \\
\hline DHD & $\begin{array}{l}\text { Days from planting to heading (also known as } \\
\text { flowering) }\end{array}$ \\
\hline ICP-MS & Inductively coupled plasma mass spectrometry \\
\hline LOD & Logarithm of the odds ratio \\
\hline lpa & Low phytic acid \\
\hline LS Mean & Least squares mean \\
\hline Mbp & $\begin{array}{l}\text { Mega base pairs, indicates physical location on } \\
\text { a chromosome }\end{array}$ \\
\hline LT-RIL & $\begin{array}{l}\text { Recombinant inbred line derived from } \\
\text { 'Lemont' } \times \text { 'TeQing' }\end{array}$ \\
\hline MIM & Multiple interval mapping \\
\hline MIPS & Myoinositol 1-phosphate synthase \\
\hline ppm & Parts per million \\
\hline QTL & $\begin{array}{l}\text { Quantitative trait locus (QTLs, quantitative trait } \\
\text { loci) }\end{array}$ \\
\hline RFLP & Restriction fragment length polymorphism \\
\hline RIL & Recombinant inbred line \\
\hline SSR & Simple sequence repeat \\
\hline TIL & $\begin{array}{l}\text { A TeQing-into-Lemont backcross introgression } \\
\text { line }\end{array}$ \\
\hline
\end{tabular}

\section{Introduction}

As one of the most important staple crops, rice provides more than $40 \%$ of the daily calories for the world's population (Parengam et al. 2010). Although rice is not considered a concentrated source of any particular mineral or vitamin, for those dependent on a rice subsistence diet, rice can be an important source of not just caloric energy, but also of vitamins and minerals important for human health. On the other hand, some elements, such as As and $\mathrm{Cd}$, contained in grain and other food products can be harmful to human health if consumed in excess. Additional minerals, although not important for human health, impact the nutrition of the plant.

Despite the importance of essential minerals for human and plant health and despite the well-developed use of rice as a plant model for genetic analysis, the genetic mechanisms controlling the accumulation of the various mineral elements ( $a k a$ the ionome) in rice remain largely unknown. Quantitative trait loci (QTLs) associated with seed ionomes have been reported in the genetic model species Arabidopsis thaliana (Baxter et al. 2012b; Bentsink et al. 2003; Waters and Grusak 2008), as well as in maize (Baxter et al. 2012a). Four rice studies have reported QTLs associated with accumulation of nutritional and potentially toxic elements in rice grain (Ishikawa et al. 2005; Lu et al. 2008; Norton et al. 2010; Stangoulis et al. 2007). The earliest of these rice studies (Ishikawa et al. 2005) utilized a set of chromosome segment substitution lines (CSSLs) and identified three QTLs associated with Cd concentration. Stangoulis et al. (2007) used liquid chromatography and inductively coupled plasma optical emission spectrometry to study the concentration of phytate and five elements $(\mathrm{P}, \mathrm{Fe}, \mathrm{Zn}$, $\mathrm{Cu}$ and $\mathrm{Mn}$ ) in a doubled haploid mapping population. $\mathrm{Lu}$ et al. (2008) used atomic absorption spectrometry to measure grain concentrations of $\mathrm{Fe}, \mathrm{Zn}, \mathrm{Ca}, \mathrm{Mn}$ and $\mathrm{Cu}$ with which to identify grain element QTLs segregating within a set of rice recombinant inbred lines (RILs). Norton et al. (2010) used atomic absorption spectrometry to evaluate concentrations of $\mathrm{Ca}$ and $\mathrm{Mg}$ in rice grain and leaves, plus inductively coupled plasma mass spectrometry (ICP-MS) to evaluate an additional 15 elements to identify ionomic QTLs segregating among an $\mathrm{F}_{6}$ indica $\times$ japonica mapping population. The present study sought to identify QTLs affecting concentrations of one or more minerals in rice grain by studying two mapping populations derived from the same two parents with the anticipation of validating some of the QTLs through identification in both populations. Grain concentrations of 16 elements were observed simultaneously in order to test if QTL regions affected grain accumulation of individual or multiple elements. The first population was a set of 'Lemont' $\times$ 'TeQing' (japonica $\times$ indica) recombinant inbred lines (LT-RILs) similar in genetic structure to the mapping population analyzed by Norton et al. (2010), while the second population was a companion set of TeQing-intoLemont backcross introgression lines (TILs) similar in genetic structure to the CSSLs observed by Ishikawa et al. (2005).

Flooding of rice paddies is known to alter soil chemistry and nutrient availability (Arao et al. 2009; Daum et al. 2002; Patrick and Khalid 1974; Patrick and Jugsujinda 1986; Zhang et al. 2004). Rice plant anatomy also differs depending on whether the plant is grown under flooded (anaerobic) or unflooded (aerobic) conditions (Hoshikawa 1989; Steffens et al. 2011; Uga et al. 2012). To enhance detection of QTLs affecting grain element concentrations, the TIL population was grown under two contrasting field conditions, flooded fields (reduced soil conditions) and regularly irrigated but unflooded fields (aerated soil conditions). 
It is known that elements often accumulate more in one portion of the rice grain than others (Hansen et al. 2012; Liang et al. 2008; Lombi et al. 2009). Since the ratio of bran to endosperm (surface to volume) is greatly affected by grain shape (length, width, thickness), data on grain shape dimensions were included in the present study. Soil temperatures can impact soil chemistry and element availability, and air temperatures impact plant transpiration which can in turn affect nutrient uptake, transport, and accumulation in aerial portions of plants (Grusak and Pomper 1999; Quintana et al. 1999; Tani and Barrington 2005; Xiloyannis et al. 2001). Because temperatures are not constant throughout the Texas growing season, but are known to grow hotter from March through mid- to late-July, then cool again; date of flowering (a.k.a. heading date) was also recorded as a possible confounding factor due to different temperature regimes during grain-fill. In graminaceous plants, including rice, nutrients taken up by the roots are often not transported directly to the grain but are redirected to/from leaves or upward at the stem nodes which can result in a gradient of elemental concentration from lower to upper stems and leaves (Hoshikawa 1989; Kuramata et al. 2013; Uraguchi and Fujiwara 2012; Yamaji and Ma 2009). Data on plant height were included as well, because plant height is correlated with the number of culm nodes between roots and panicles (Samonte et al. 2005).

\section{Materials and methods}

\section{Genetic materials}

Putative ionomic QTLs were first identified in a set of 280 (RILs) derived from a cross between cultivars Lemont and TeQing hereafter referred to as the LT-RILs. Lemont (PI 475833 ) is a US tropical japonica rice cultivar with longgrain shape and earlier maturity than TeQing (PI 536047), an indica cultivar from China having medium-grain shape. The LT-RILs have been highly characterized and used in numerous QTL mapping studies including identification of loci affecting grain weight and shape (Li et al. 1997; Xu et al. 2004), grain yield (Li et al. 1997, 1998; Tong et al. 2006), plant architecture (Li et al. 1995, 1998, 1999b; Mei et al. 2005; Pinson et al. 2005), days to flowering (Pinson et al. 2005, 2012), and disease resistance ( $\mathrm{Li}$ et al. 1999a; Pinson et al. 2005, 2010; Tabien et al. 2000, 2002). By mapping ionomic QTLs in this highly characterized population, the genomic location of newly identified ionomic loci could be readily compared with loci previously reported for other traits. Concentrations of LT-RIL grain elements were evaluated in seed samples produced and harvested over five different years, 2002, 2003, 2006, 2007 and 2008 at which time the field plants were in the $\mathrm{F}_{15}, \mathrm{~F}_{16}$, $\mathrm{F}_{17}, \mathrm{~F}_{18}$ and $\mathrm{F}_{19}$ generations, respectively.

The second mapping population in the study consisted of 123 TILs that contain molecularly tagged portions of the TeQing genome introgressed into the predominantly US tropical japonica genetic background of Lemont (Pinson et al. 2012). The TILs have been characterized for 159 simple sequence repeat (SSR) loci, and only backcross progeny found to contain $\geq 65 \%$ Lemont alleles were included in the final set of 123 TILs. All portions of the TeQing genome are now represented across the set of TILs. Sets of chromosome segment substitution lines such as the TILs can also be used for de novo QTL mapping as well as QTL verification.

Planting and phenotypic evaluation of the LT-RIL population grown under flooded field conditions

A total of five replications of LT-RIL seed were evaluated for grain element concentration, with one replication produced per year over 5 years (2002, 2003, 2006, 2007, and 2008). From five to seven repeated plots of the two parents, Lemont and TeQing, were randomized among the LT-RIL plots each annual replication. All LT-RIL plots were grown in Beaumont, TX under flooded paddy conditions, planted into soil classified as League clay (fine, smectitic, hypothermic Oxyaquic Dystrudert; USDA, 1999). Plots received $33.6 \mathrm{~kg} / \mathrm{ha} \mathrm{P}$ as preplant fertilizer and $73 \mathrm{~kg} / \mathrm{ha} \mathrm{N}$ (as urea) at the time of planting. Plots were drill-seeded approximately $2 \mathrm{~cm}$ deep using a Hege 80 Plot Seeder (Wintersteiger Ag, Dimmelstrasse 9, 4910 Ried/I., Austria). Germination was initiated when a flush irrigation moistened the soil. Additional flush irrigations were applied as needed to maintain soil moisture until seedlings were approximately $18 \mathrm{~cm}$ tall, at which time an $8-16 \mathrm{~cm}$ depth flood was applied and maintained on the fields until the last plots per field were harvested. Maintenance of the flood throughout the grain-fill periods of all genotypes was considered crucial since even short periods of field drainage have been shown to significantly impact soil chemistry, which in turn affected grain mineral concentrations, especially when the soil drainage occurred shortly before or during the grain-fill period (Arao et al. 2009; Daum et al. 2002).

The heading time of the earliest versus latest LT-RILs was previously found to differ by as much as 85 days (Pinson et al. 2005), causing concern that the early versus late heading LT-RILs would likely experience significantly different air and water temperatures during grain-fill, which would cause different plant transpiration and water uptake rates, and could potentially alter soil nutrient availability as well. In three of the five study years $(2002,2003$, and 2006), the heading time between the various LT-RILs was better synchronized by dividing the population into four 
portions based on prior flowering observations, and planting them into neighboring field paddies at 7- to 10-day intervals with the RILs known to have longer intervals between seeding and flowering being planted first, and RILs known to flower in shorter time being planted last. This staggered planting resulted in more than $90 \%$ of the LT-RILs flowering within a 3-week span in 2002, 2003, and 2006. Seeds of the LT-RILs and check varieties were drill-planted into plots consisting of 5 rows each, $2.4 \mathrm{~m}$ long, with $28 \mathrm{~cm}$ spacing between the rows within plots, as well as $28 \mathrm{~cm}$ spacing between the plots. Approximately 75 seeds were planted per row, with grain for analysis being obtained from the inner three rows of each 5-row plot. Approximately, $46,500 \mathrm{~m}^{2}$ of field space was required to plant each replication of the LT-RILs in 2002, 2003, and 2006.

In contrast, the field plots planted in 2007 and 2008 were planted in a manner that significantly decreased the field area (and presumably soil variance) within and between replications, but also necessitated that all plots be drill-seeded on a single day. The 2007 and 2008 field plots consisted of five seeds per genotype drill-seeded into $13-\mathrm{cm}$ length lines, hereafter called hillplots. Five hillplots were planted per field-row with $60 \mathrm{~cm}$ between hillplots within each field-row, and $25 \mathrm{~cm}$ between rows. Each replication consisted of one plot per LT-RIL plus seven plots per parental genotype planted over a $67 \mathrm{~m}^{2}$ area in both 2007 and 2008.

The date of $50 \%$ heading was recorded for each 5-row plot in 2002, 2003, and 2006, and per individual hillplot in 2007 and 2008. Days to heading (DHD) was calculated by subtracting the date of first irrigation after planting from the heading date recorded for each plot. All plots were hand harvested between 22 and $15 \%$ grain moisture. Rough rice samples were dried to $12 \%$ moisture using an ambientforced-air drier and were then stored in sealed plastic boxes until phenotypic analysis.

Planting and phenotypic evaluation of the

TeQing-into-Lemont introgression lines (TILs) grown under both flooded and unflooded field conditions

The TILs were planted into hillplots in 2007 and 2008, and fertilized as described for the LT-RILs. Each TIL replication included 15 plots each of Lemont and TeQing. In order to study the putative ionomic QTLs under contrasting soil redox and plant development conditions, the TILs were grown in both flooded (anaerobic conditions) and unflooded (aerobic) fields. The unflooded fields were flush irrigated as needed to prevent water stress throughout the growing season, with water held on the field 5-14 h per flush. Two replications per water treatment were planted in both 2007 and 2008, but, due to storm damage, seed was harvested from two flooded plus one unflooded replications in 2007, and one flooded plus two unflooded replications in 2008. Heading date was observed and seed was hand harvested as previously described for the LT-RILs.

Measurement of grain length, width and thickness

Rice grain dimensions (length, width, and thickness) of each of the LT-RILs and check varieties were measured using seed harvested in 2002 and 2003. TIL kernel dimensions were collected from seed harvested from a single flooded replication in each of 2 years, 2007 and 2008. For each plot, 100 whole brown rice kernels were produced with a Satake TH035A sheller (Satake Engineering Co. Ltd., Tokyo, Japan). They were then scanned with a WinSeedle Pro 2005aTM image analysis system (Regent Instruments Inc.; Sainte-Foy, Quebec, Canada) for determination of mean grain length (GL) and grain width (GW) in $\mathrm{mm}$. Grain thickness (GT) of brown rice was measured in $\mathrm{mm}$ with a digital micrometer on a subset of 20 kernels. Since bran:endosperm ratio is strongly affected by kernel roundness, which is determined by a combination of these dimensions, we also approximated grain volume $(\mathrm{GV})$ by multiplying GL $\times \mathrm{GW} \times$ GT. Kernel dimension data were averaged across the 2 years prior to QTL analysis.

\section{Analysis of grain element concentration}

Using ICP-MS (Perkin-Elmer Elan DRCe ICP-MS), rice grain samples were simultaneously analyzed for concentrations of 16 elements. To validate the accuracy of the ICPMS analytical method used in this study we first analyzed the NIST standard reference material 1568a (rice flour). The error reported on the NIST certified reference material for $\mathrm{Mn}, \mathrm{Fe}, \mathrm{Cu}, \mathrm{Zn}$, and $\mathrm{Cd}$ ranged from \pm 3 to $\pm 12 \%$. The percentage of errors we observed, calculated as the NISTcertified value as compared to the value we obtained using our ICP-MS-based analysis for the same element, ranged from 5 to $13 \%$, and was not significantly different from the NIST expected errors. The convention in this report will be to report mineral concentrations as micrograms per gram grain dry weight (ppm), and to present the five plant macronutrients first, in high to lower order of their grain concentration, followed by the remaining 11 elements in alphabetical order. This results in the order of $\mathrm{P}, \mathrm{Mg}, \mathrm{K}, \mathrm{S}$, $\mathrm{Ca}, \mathrm{As}, \mathrm{Cd}, \mathrm{Co}, \mathrm{Cu}, \mathrm{Fe}, \mathrm{Mn}, \mathrm{Mo}, \mathrm{Ni}, \mathrm{Rb}, \mathrm{Sr}, \mathrm{Zn}$ used in all tables and diagrams. Kernels for ICP-MS analysis were dehulled using a Satake TH035A sheller (Satake Engineering Co. Ltd., Tokyo, Japan) modified by replacing the rubber liner on the rollers with PU40 Polyurethane plastic. This modification prevented contamination of the rice samples with rubber particles, which are known to contain $\mathrm{Zn}$ (Stangoulis 2010). 
We took two approaches to determine the optimal number of grains for ICP-MS analysis of each plot sample: a simulation approach based on single grain analysis and a purely theoretical simulation based approach. Because we were limited to parent data and to simplify the simulations, we focused on the power to detect difference between the two parents. It should be noted that this type of comparison is significantly less powerful than the QTL analysis performed with the RILs, but it allowed us to set a floor in terms of our detection power.

We started with a set of Lemont and TeQing seeds from a single 2006 planting date. Seed of these parental plots was hand harvested in two ways in 2006 , collecting a set of five individual panicles as well as row-bulks (mix of all grain from $\geq 7$ plants per row). The row-bulks were used for the preliminary studies, reserving the panicle harvests for the actual QTL study. After removing visibly green kernels, 10 grains were randomly selected from 6 and 3 rowbulks, respectively for Lemont and TeQing, and analyzed for ionomics as individual kernels (providing individual kernel data on 60 Lemont grains and 30 TeQing grains). The difference of the means of the two genotypes across all grains ranged from 0 to $77 \%$ for the 16 elements. For each sample size between 3 and 20, we created 200 datasets by randomly picking samples from the parent data then used a $t$ test to determine the significance level of the Lemont to TeQing difference for each dataset pairing (Supplemental Fig. 1). Analysis of the $n=3-20$ subsets indicated that for some elements (e.g., $\mathrm{Mg}, \mathrm{Co}$, and $\mathrm{Ni}$ ) even sample sizes as large as 20 were unlikely ( $<10 \%$ of the time) to detect differences between Lemont and TeQing. In contrast, more than $95 \%$ of the smallest subsamples ( 3 kernels) were able to detect a difference for $\mathrm{Zn}$, followed by $60 \%$ of the samples detecting a difference for $\mathrm{As}, \mathrm{Cu}$, and $\mathrm{Mn}$. This indicated that samples as small as 3-kernels could support the identification of at least some grain element QTLs.

We also simulated datasets with three known levels of mean difference between each line $(20,50$ and $100 \%)$ and four levels of relative standard deviation (RSD) $(10,30,50$ and $100 \%$ ). These simulations showed that while a sample size of $n=3$ would limit the power to detect small differences (10-20\%), especially for elements with high RSDs within the system, differences $>50 \%$ for elements with RSDs $<30 \%$ would be likely to be detected (Supplemental Fig. 2). Logistically, a three grain sample was the easiest size to handle (e.g., reliably digest completely) with the available equipment. As only two of the 16 elements (Ni and Cd) had RSDs $>30 \%$ and a $50 \%$ difference could be easily fine-mapped in followup experiments, we chose to conduct all further analyses with three grain samples. Furthermore, the seeds phenotyped for the QTLs analyses were anticipated to be significantly more uniform per plot for grain maturity, size, and protein and starch chemistry than the row-bulks evaluated in the preliminary analyses due to careful sampling per plot as described below.

It has long been known that the rice grain starch and protein chemistry are impacted by the position of a rice grain along a single panicle (Dong et al. 2007; Liu et al. 2005) as well as differences in grain maturity and even air temperature during grain-fill (Harris and Juliano 1977; Resurreccion et al. 1977). Due to concern that that these factors might also be impacting grain element concentrations, the grains phenotyped for QTL analysis included only fullymature kernels collected from the upper 1/4th $(6 \mathrm{~cm})$ of early-maturing panicles harvested per plot. Thus grains phenotyped for QTL analysis were expected to be from primary culms as opposed to later tillers, and significantly less variable per plot than the row-bulked seed used for the preliminary analyses. Approximately 20 kernels were selected from $\geq 3$ panicles per plot harvest and dehulled. From this, three whole, non-diseased grains of mature brown rice were selected, weighed (approx. $0.05 \mathrm{~g}$ ), and digested with $1.0-\mathrm{m} 1$ concentrated $\mathrm{HNO}_{3}$ in $16 \times 100 \mathrm{~mm}$ Pyrex tubes at temperatures stepped from ambient to $110^{\circ} \mathrm{C}$ over a period of $12 \mathrm{~h}$. Indium (EM Science) was added to the acid to a final concentration of $20 \mu \mathrm{g} \mathrm{L}^{-1}$ as an internal standard. Samples were diluted to $10.0 \mathrm{~mL}$ and analyzed on a PerkinElmer Elan DRCe ICP-MS (Perkin-Elmer Corp., Norwalk, CT, USA) for the following isotopes P31, K39, Mg25, S34, Ca43, As75, Cd114, Co59, Cu65, Fe57, Mn55, Mo98, Ni60, Rb85, Sr88, and Zn66. To normalize data between machine runs in order to correct for drift, portions of the samples were combined and used as a matrix-matched standard, measured after every nine samples. Samples were normalized to the averaged signals of the best-measured elements and weights of seven samples per run. All ICP-MS data on rice grain used in this study is publically available at http://www.ionomicshub.org.

\section{Analysis of variance (ANOVA)}

One-way ANOVAs were conducted using JMP (version 9.0.0; SAS 2010) to partition the total phenotypic variance observed for each element into genetic, planting method, and year (nested within planting method) effects.

\section{Calculating trait means and correlations}

Using SAS (version 9.1), the least squares (LS) means of each trait for each LT-RIL and parental genotype were calculated across the 5 years-replications, and across the three replications of TIL data, keeping the data from flooded and unflooded field conditions separate. Also, LS means were calculated for the LT-RILs grouped according to planting method, with the data from 2002, 2003, and 2006 representing staggered-planting into 
large plots, versus the 2007 and 2008 data representing hillplot planting on a single day per replication. Using JMP, Pearson's correlation coefficients were calculated between each pair of all 16 elements, and between the 16 elements with grain shape, days to heading, and plant height. Heading date (DHD) and plant height ( $\mathrm{Ht}$, in $\mathrm{cm}$ ) observed in a previous LT-RIL study (Pinson et al. 2005) were included in the LT-RIL correlations in addition to the DHD observed in the 2002-2006 stagger-planted plots. Likewise, TIL DHD data was from Pinson et al. (2012), and Ht data for the TILs came from yet another row-plot study (Pinson unpublished). Because the use of multiple comparisons can increase type I error, significance thresholds were determined using Bonferroni's adjustments (Abdi 2007).

Identification of QTLs in the Lemont-TeQing recombinant inbred population (LT-RILs)

Genotypic data consisted of 176 predominantly RFLP marker loci, determined in $\mathrm{F}_{10}$ LT-RILs by Tabien et al. (2000), and used previously in several disease resistance QTL mapping studies that utilized earlier generations of this LT-RIL population ( $\mathrm{Li}$ et al. 1999a, b; Pinson et al. 2005, 2010; Tabien et al. 2000, 2002). The QTLs were analyzed using both multiple interval mapping (MIM) and Bayesian information criterion (BIC) analyses conducted on individual replication (year) data as well as on LS Means calculated per genotype across the multiple replications. QGene version 4.3.4 (Joehanes and Nelson 2008) was used to conduct single-trait MIM (Kao et al. 1999); BIC analyses were conducted as described by Zhang et al. (2005, 2008; Zhang 2010) using SAS 9.1.3 (SAS 2007). Because the results of the 5-year LS Mean MIM analyses provided comprehensive coverage of the QTLs identified in two or more years from MIM and BIC analysis of individual year data, and included all QTLs identified from analysis of LS means per planting method, only results from 5-year LS mean MIM analyses are included in the following tables and figures. The MIM analyses of trait LS means were conducted using a window size of $15 \mathrm{cM}$ and a limit of three cofactors per element or single-trait MIM. The LOD thresholds for use in the MIM analyses were determined within QGene, using 1,000 permutations for each set of element data. The permuted LOD thresholds $(\alpha=0.10)$ for all 16 elements proved quite similar across the years, ranging from 2.9 to 3.2. In that permuted LODs are estimates rather than definitive thresholds, it was decided to use a uniform LOD threshold of 3.0. The percentage of phenotypic variance explained by each QTL was equal to the generalized $R^{2}$ values calculated by the QGene single-trait MIM analyses (Nagelkerke 1991).
Marker-trait associations among the TeQing-into-Lemont introgression lines (TILs)

Associations between the TIL SSR markers (markers determined by Pinson et al. 2012) and the observed grain traits were evaluated using the Marker-Trait Association module in JMP/Genomics 5.0 (SAS 2009). This module uses ANOVA to test for association between a trait and marker genotypes using a single marker at a time. The negative $\log 10$ (NegLog10) conversion was used on all $p$ values and the false discovery rate (FDR) multiple testing correction was calculated (Benjamini and Hochberg 1995; Weller et al. 1998) and applied to identify markers significantly associated $(\alpha=0.1 ; p$ value threshold $\leq 0.0036)$ with one or more of the grain concentrations of the 16 elements. The markers with significant $p$ values were then arranged according to their reported chromosomal locations (Pinson et al. 2012; Fig. 2). When multiple linked SSRs were found to have significant association with (and similar additive effect on) a grain element, the linkage association is indicated just once in the tables and figures, with the element names aligned by the marker that exhibited the highest association for that element in that genomic region beside dashed lines that indicate all markers found to be significantly associated with that and other linked elements. Each marker-trait ANOVA produced an estimated LS Mean value which is interpreted as the difference between the genetic effects of the TeQing/TeQing and the Lemont/Lemont (control) genotypes, which is also equal to $2 \times$ the additive effect. Physical locations of the SSR and RFLP markers reported in the Gramene database (http://www.gramene. org) were used to align the SSR and RFLP marker maps, and are reported here based on the markers' Mbp locations on the Gramene Annotated Nipponbare Sequence 2009 map.

\section{Results}

Planting date affected DHD but not grain element concentrations among the stagger-planted LT-RILs

The staggered-planting dates employed in the 2002, 2003, and 2006 LT-RIL studies successfully narrowed the period of heading time and thus decreased the variance in day length, light intensity, and air and soil temperatures during grain-fill among the LT-RILs (results not shown). However, the potential for spatial variability in soil type and nutrient availability was considered high due to the staggered-planting dates across a large field area. Although differences due to planting date cannot be distinguished from locational soil differences between the staggered-planting blocks which were arranged from east to west each year, data from 
the 5 to 7 repeated plots of Lemont and TeQing that were included in each of the staggered-planting blocks were used to evaluate differences between the planting blocks per year. Within the repeated check plots observed in and across 2 years (2003 and 2006, no seed from 2002 check plots remained available for ionomic analysis), none of the 16 elements exhibited a consistent significant $(\alpha>0.05)$ relationship with planting time or directional field location (data not shown). Consequently, concentrations of the 16 elements were not adjusted for within field location or planting time, but raw data used for further evaluation of means, variances, and correlations within, between and across years. In contrast, planting time was found to significantly and consistently affect the number of days from seeding to DHD. In all three stagger-planted years, the earlier planted Lemont and TeQing plots had longer vegetative stages than plots planted at later dates, likely due to a combination of longer day lengths and warmer temperatures as the season progressed. Lemont and TeQing similarly showed an average reduction in vegetative phase of 0.33 day for every day delay in planting across all 3 years. Thus, the Pearson correlations (Table 1) considered two sets of DHD data, one set observed from a prior study where the LT-RIL plots were planted on a single day (Pinson et al. 2005) in comparison with the DHD data collected from stagger-planted plots in 2002, 2003, and 2006.

Genotype and year contributed more to phenotypic variance than planting method

The proportion of phenotypic variance explained by genotype is also known as broadsense heritability $\left(H^{2}\right)$. The average $H^{2}$ among the 16 elements was 0.40 , and was greater than 0.30 for all elements except $\mathrm{Ni}$ which had $H^{2}=0.03$ (Table 2). The highest heritabilities were seen for $\mathrm{Mg}$, Mo and $\mathrm{Sr}$ which had $H^{2}>0.50$. On average, more variance was attributed to years than planting methods, but was again variable per element. Planting method explained $<1 \%$ of the variance observed for grain concentrations of $\mathrm{Mg}, \mathrm{Fe}$, and $\mathrm{Rb}$. In contrast, for two of the 16 elements, As and $\mathrm{Zn}$, planting method explained significantly more variance than years $(1.5 \times$ more for As, $2.6 \times$ more for $\mathrm{Zn})$. A different field location was planted each year, and because the stagger-planted 2002, 2003, and 2006 field plots were significantly closer to each other (maximum distance between plots across these years $\approx 250 \mathrm{~m}$ ) than the field areas planted in 2007 and 2008 ( $\geq 900 \mathrm{~m}$ away), the proportions of variance attributed by ANOVA to 'Planting method' and 'Year' are both potentially confounded by differences in soil mineral availability. It is especially interesting, then, that that the pairwise correlations between years (Supplemental Table 1) shows that the year most closely correlated across all elements with either of the hillplot years (2007 and 2008) is
2002, a relatively distant stagger-planted year. The ANOVA and correlation results indicate that annual seasonal differences were a larger source of variance in grain element concentrations than were planting method or geographical distance. Accordingly, the remainder of the LT-RIL results and discussion focus on LS means calculated across all 5 years.

Trait averages, ranges and correlations

Histograms determined from the LS mean data calculated across all 5 years for each element concentration per LTRIL (Fig. 1) show multiple LT-RILs with grain concentrations higher and/or lower than the parental means \pm 1 standard deviation, indicating transgressive segregation among the LT-RILs for all 16 grain elements. For some elements (e.g. $\mathrm{P}, \mathrm{Cu}$, and $\mathrm{Sr}$ ), transgressive segregation contributed significantly to the variance observed among the LT-RILs for that mineral, while for other elements (e.g. Ni and $\mathrm{Fe}$ ) it was relatively minor. Transgressive segregation was observed among the LT-RILs even when the Lemont and TeQing parental values were not significantly different, e.g. P, Ca, Fe and Sr. These results suggested that the LTRILs are segregating for genetic loci (QTLs) affecting the concentration of that element in rice grain, and that both Lemont and TeQing contributed alleles for increased element accumulation. Averages \pm 1 standard deviations of the grain and plant traits observed in each individual year/ replication among the parental lines, LT-RILs, and TILs can be viewed in Supplemental Table 2.

The Pearson correlations $(r)$ determined between traits among the LT-RILs based on 5-year means are presented in Table 1a; correlations observed among the TILs (means across three replications) grown under flooded and unflooded field conditions are compared in Table $1 \mathrm{~b}$. The correlations shown in the boxes in Table 1a are the averages of the year-toyear correlations per element (Supplementary Table 1). Grain dimension traits exhibited the highest correlations between years. Among the elements, $\mathrm{K}, \mathrm{Mg}$, Mo, and $\mathrm{Sr}$ showed especially high correlation between years $(r>0.40)$, while As, $\mathrm{Cd}, \mathrm{Fe}$, and $\mathrm{Ni}$ exhibited more sensitivity to environmental variance. While not a perfect correlation, these elements were also generally among those determined by ANOVA to have the most extreme heritabilities (Supplementary Table 1).

Some interesting patterns can be seen among the correlations between the various elements. Correlation between three essential macronutrients $\mathrm{P}-\mathrm{K}, \mathrm{P}-\mathrm{Mg}$, and $\mathrm{Mg}-\mathrm{K}$ are highly significant and positively correlated in both the LTRILs and the TILs, under both flooded and unflooded conditions (Table 1). Other correlations that were significant over all populations, planting method, and field water treatments include $\mathrm{Ca}-\mathrm{Sr}$ (positive), $\mathrm{Fe}-\mathrm{K}$ (negative), and $\mathrm{Mn}-\mathrm{Cd}$ (positive). Of the 42 element-element correlations that were significant among the LT-RILs, 21 (50\%) proved significant 
Table 1 Correlations between traits in the LT-RIL and the TIL populations

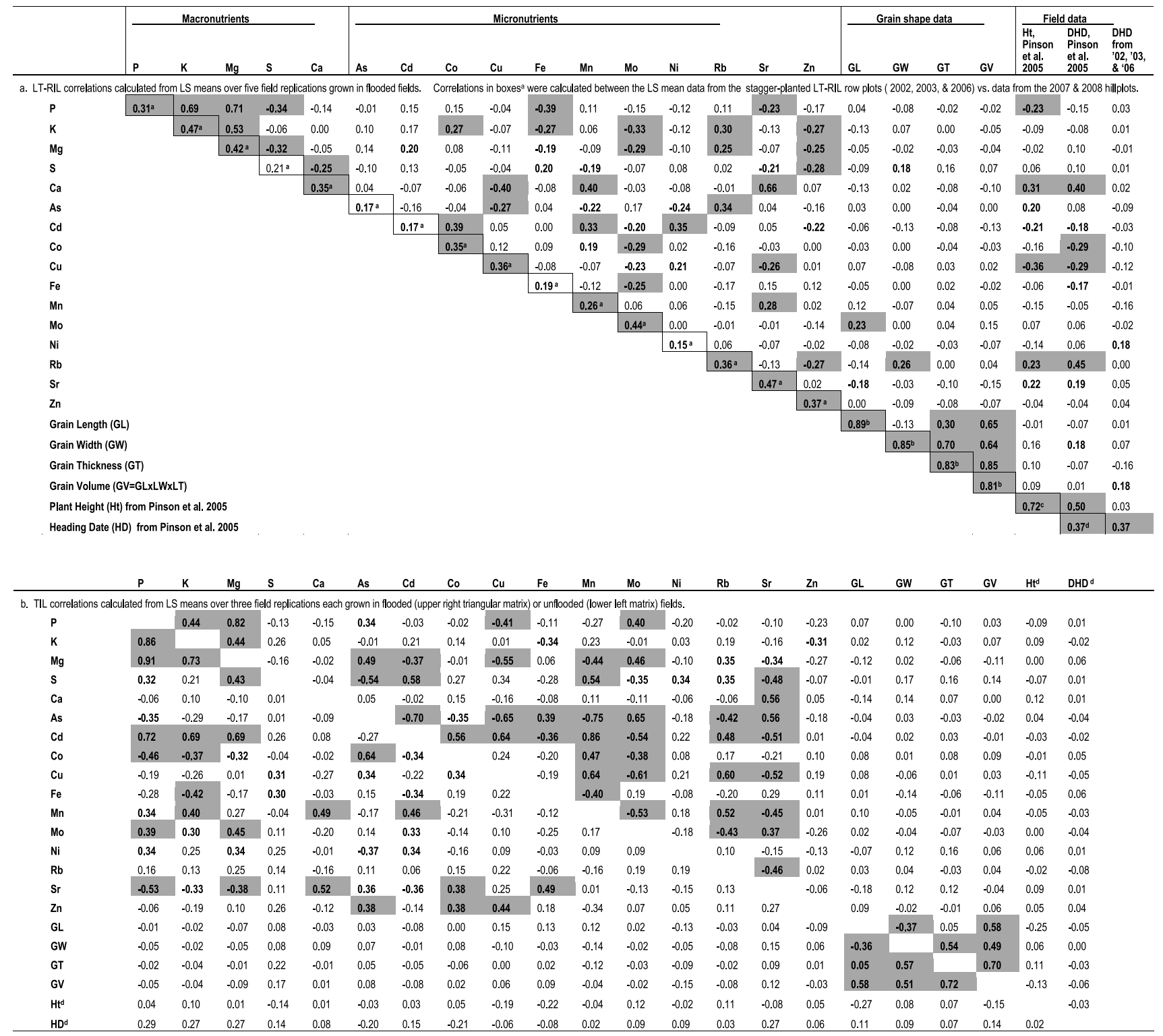

Correlations between traits (grain element concentrations [ppm], grain shape, plant height, and days to heading) for the LT-RILs calculated from LS mean data across five field replications, all grown flooded. The averages of the pairwise correlations between the five LT-RIL years for each element are in the boxed cells. TIL data were analyzed separately for the flooded versus unflooded field conditions, and were grown only as hillplots in 2007 and 2008

Significance Levels: Bold text significant at the $\alpha=0.05$ level, Shading of cells indicates significance at the $\alpha=0.01$ level. Bonferoni adjustments were used to account for the multiple comparisons made

${ }^{a}$ Averages of the pairwise correlations between years reported in Supplementary Table 1

b The between-year correlations for grain shape attributes were calculated from measurements made on 2002-harvested seed versus shape data from seed harvested in 2003

c Correlations between the LT-RIL heading dates observed by Pinson et al. (2005) versus data presently collected from 2002, 2003, and 2006 stagger-planted plots

d TIL Height (Ht) and data on days to heading (DHD) data were from other field plots grown for other studies (Ht unpublished, DHD Pinson et al. 2012)

also among the TILs. The dataset revealing the highest number of significant element-element correlations was that of the TIL population grown under flooded field conditions.
Among the TILs, whether grown flooded or unflooded, none of the grain elements were significantly correlated with grain shape, plant height, or DHD. In contrast, among 
Table 2 Percentages of total phenotypic variance explained by genotype, planting method, and year

\begin{tabular}{lrrr}
\hline & Genotype $^{\mathrm{a}}$ & Planting method $^{\mathrm{b}}$ & Year $^{\mathrm{b}}$ \\
\hline $\mathrm{P}$ & 34.3 & 3.4 & 28.6 \\
$\mathrm{~K}$ & 32.5 & 18.9 & 27.1 \\
$\mathrm{Mg}$ & 52.4 & 0.2 & 11.7 \\
$\mathrm{~S}$ & 30.4 & 13.8 & 12.2 \\
$\mathrm{Ca}$ & 46.9 & 1.1 & 14.3 \\
$\mathrm{As}$ & 25.4 & 18.9 & 12.6 \\
$\mathrm{Cd}$ & 30.1 & 7.8 & 7.2 \\
$\mathrm{Co}$ & 50.6 & 2.9 & 11.1 \\
$\mathrm{Cu}$ & 46.2 & 8.2 & 9.7 \\
$\mathrm{Fe}$ & 44.6 & 0.1 & 11.6 \\
$\mathrm{Mn}$ & 50.5 & 2.1 & 3.7 \\
$\mathrm{Mo}$ & 56.3 & 2.1 & 7.7 \\
$\mathrm{Ni}$ & 3.4 & 27.3 & 50.1 \\
$\mathrm{Rb}$ & 38.0 & 0.6 & 17.9 \\
$\mathrm{Sr}$ & 58.5 & 2.3 & 9.0 \\
$\mathrm{Zn}$ & 43.4 & 16.7 & 6.4 \\
$\mathrm{Avg}$. across elements & 40.2 & 7.9 & 15.1 \\
\hline $\mathrm{M}$ & &
\end{tabular}

a The percentage of total phenotypic variance explained is also known as broadsense heritability $\left(H^{2}\right)$

b Because a different field location was used each year with the stagger-planted 2002, 2003, and 2006 fields being physically closer to each other than the field areas planted in 2007 and 2008, the variances attributed to 'Planting method' and 'Year' are both potentially confounded by differences in soil mineral availability. The ANOVA models considered 'Year' nested within 'Planting method'

the LT-RILs, Mo and Sr were significantly correlated with grain length, while $\mathrm{S}$ and $\mathrm{Rb}$ were significantly correlated with grain width. The DHD as observed in the staggerplanted LT-RIL plots was significantly correlated with just one element, Ni, while DHD as measured from LT-RIL plots planted on a single day (Pinson et al. 2005) correlated with seven elements, namely, $\mathrm{Ca}, \mathrm{Cd}, \mathrm{Co}, \mathrm{Cu}, \mathrm{Fe}, \mathrm{Rb}$, and Sr. Plant height and heading are known to be correlated among the LT-RILs (Pinson et al. 2005), and five of the elements correlated with both DHD and height.

QTLs affecting grain element concentration identified among LT-RILs and TILs

Between the LT-RIL and the TIL analyses, a total of 134 putative QTLs for concentration of specific elements in rice grain were identified (Table 3; Fig. 2). The LT-RIL MIM LOD peaks are indicated by element names to the left of the chromosomes in Fig. 2. Results of the TIL marker-trait analyses are to the right of the chromosomes in Fig. 2, with the element names placed beside the marker that exhibited the strongest statistical association and color coded to indicate significance among flooded TILs (blue), unflooded
TILs (brown), or both (black). Mapping populations consisting of introgression lines (ILs) such as the presently utilized TILs and the CSSLs in which Ishikawa et al. (2005) identified Cd QTLs, that consist of progeny lines having a common (shared) genetic background into which one or few chromosomal segments have been substituted with chromosome pieces (genes) from another source, allow scientists to observe precisely the phentoytpic effect of one or few genes per trait per line. This allows QTLs of smaller individual effect to be detected as statistically significant, and accordingly, our QTL analyses detected more QTLs segregating among TILs than among LT-RILs. However, because IL mapping populations generally contain less recombination within each chromosomal region than one finds in a RIL mapping population, the QTLs are not mapped with as much precision. The QTL location estimates determined here among the TILs are not considered precise, as indicated by the dashed lines in Fig. 2.

Analysis of the LT-RILs, flooded TILs, and unflooded TILs each identified 40, 92, and 47 specific grain element QTLs, respectively. Interestingly, the flooded TILs, where the most ionomic QTLs were identified, is also the population wherein the most significant element-to-element correlations were determined (Table 1). Non-genetic variance was higher among the unflooded replications than the flooded replications, with the coefficients of variance for the 16 elements among the multiple Lemont and TeQing check-plots planted per replication being, on average, twofold higher in the unflooded replications than the flooded replications (data not shown). One impact of such an increase in non-genetic variance would be reduced ability to identify QTLs of smaller phenotypic effect, consistent with the identification of fewer QTLs among the unflooded TILs than among flooded TILs. This was most dramatically demonstrated by Mn for which no QTLs were identified among unflooded TILs.

Confidence in a particular QTL increases when it is validated with identification in more than one population or study-environment. In this study, QTLs could be considered validated by identification among both LT-RILs and among the TILs for the same element. Alternatively, identification of a particular QTL among both the flooded and unflooded TILs would not only validate that QTL, but would also reflect the stability of that QTL across widely divergent field environments. The three left-hand columns in Table 3 indicate the populations and environments in which each QTL was found statistically significant. Among the 134 QTLs, six were considered strongly validated and stable in that they were found significantly associated with the same element among the TILs grown both flooded and unflooded as well as in the LT-RILs. For example, a QTL for $\mathrm{K}$ was identified on chromosome 1 in the LT-RILs and in the TILs grown under both flooded and unflooded field 

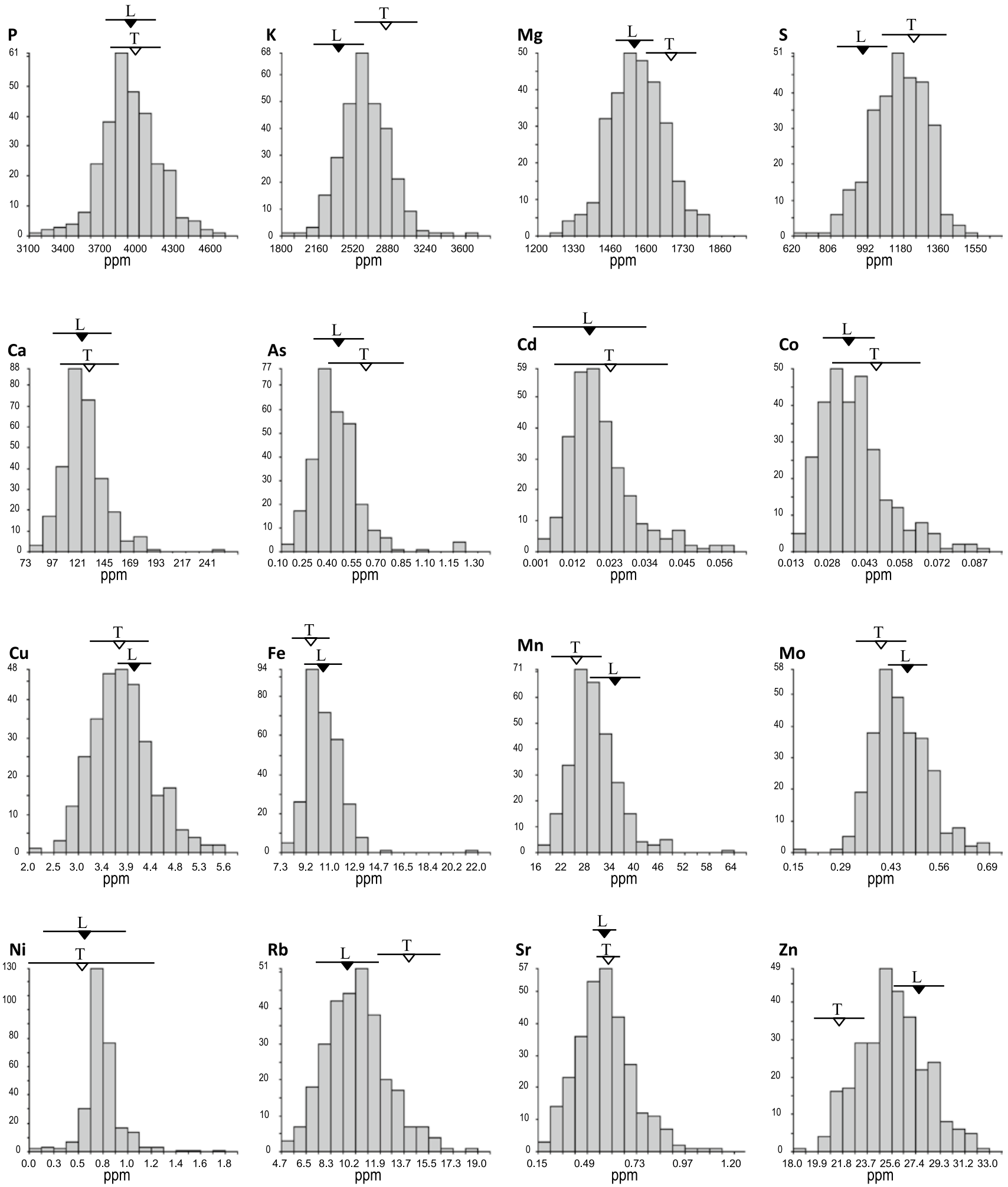

Fig. 1 Histograms showing the range of the LS means observed among the population of 280 LT-RILs for the 16 elemental traits, all LT-RIL fields were flooded till all plots were mature and harvested. Elements are listed starting with the five macroelements (those reaching $>100 \mathrm{ppm}$ in rice grains), in order of their mean grain concen-

tration, followed by the 11 remaining elements in alphabetical order. Also indicated are the LS Means ( \pm 1 standard deviation) of the multiple repeat check plots of the parental lines, Lemont and TeQing, grown in those same flooded fields 


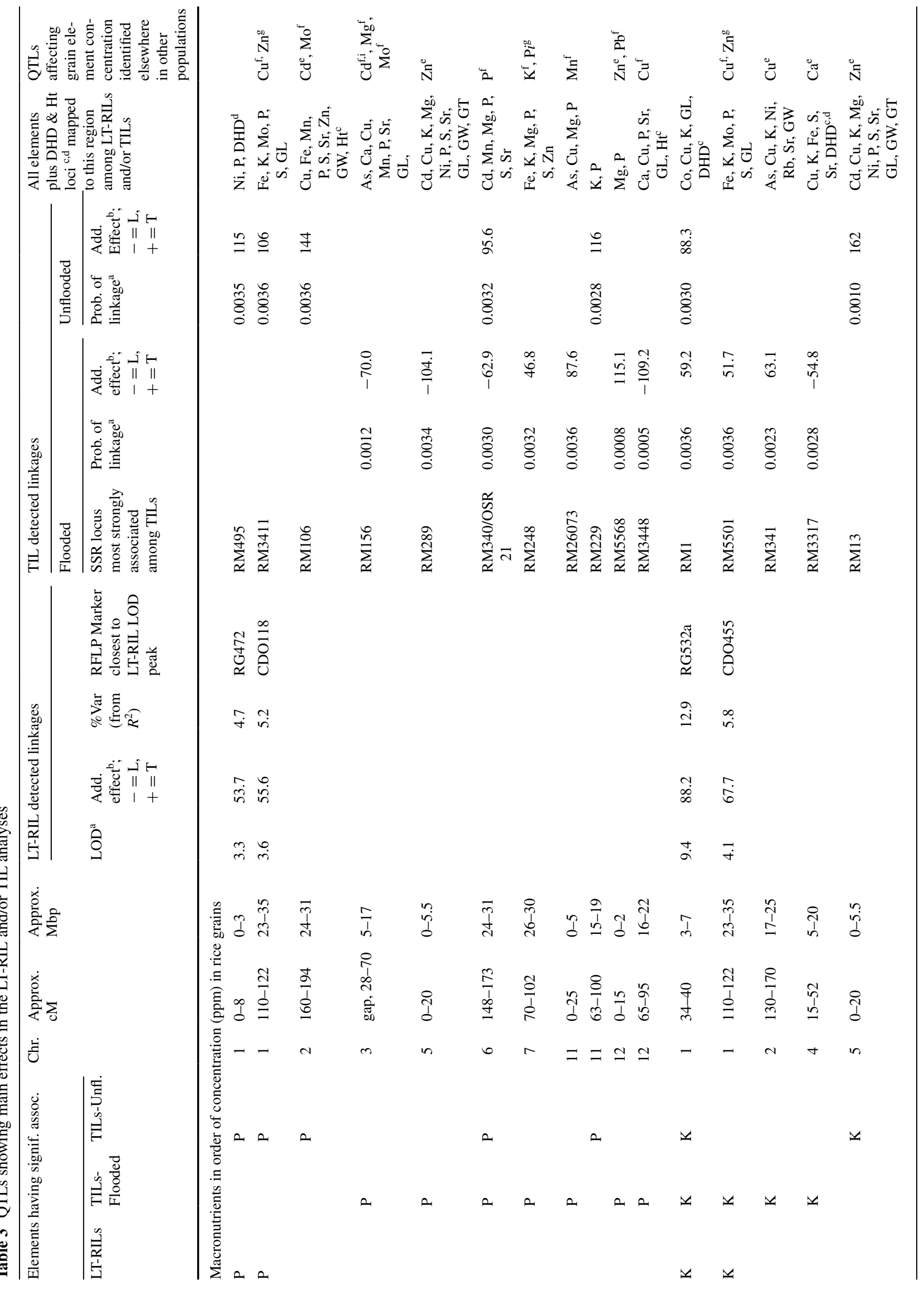




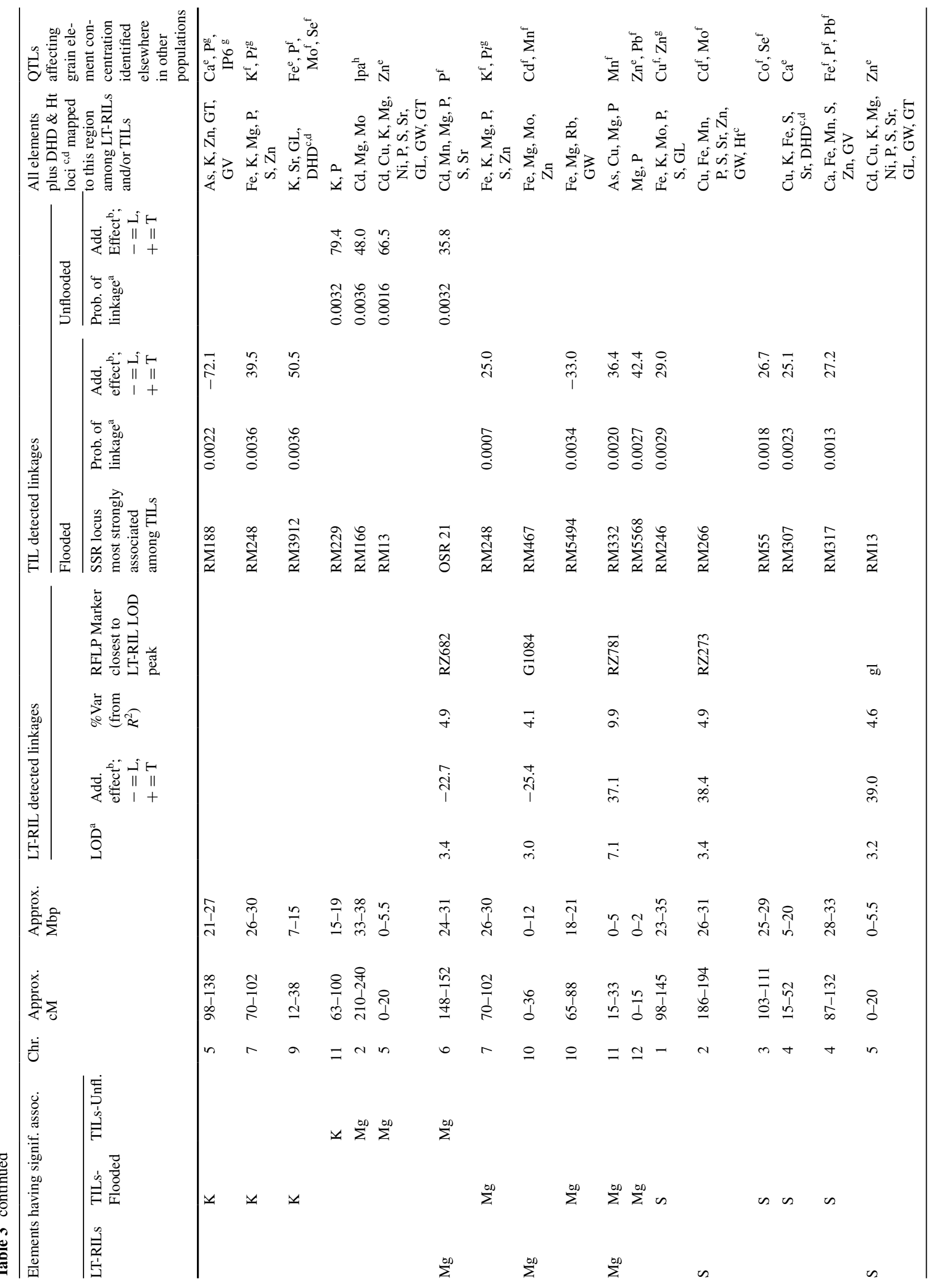




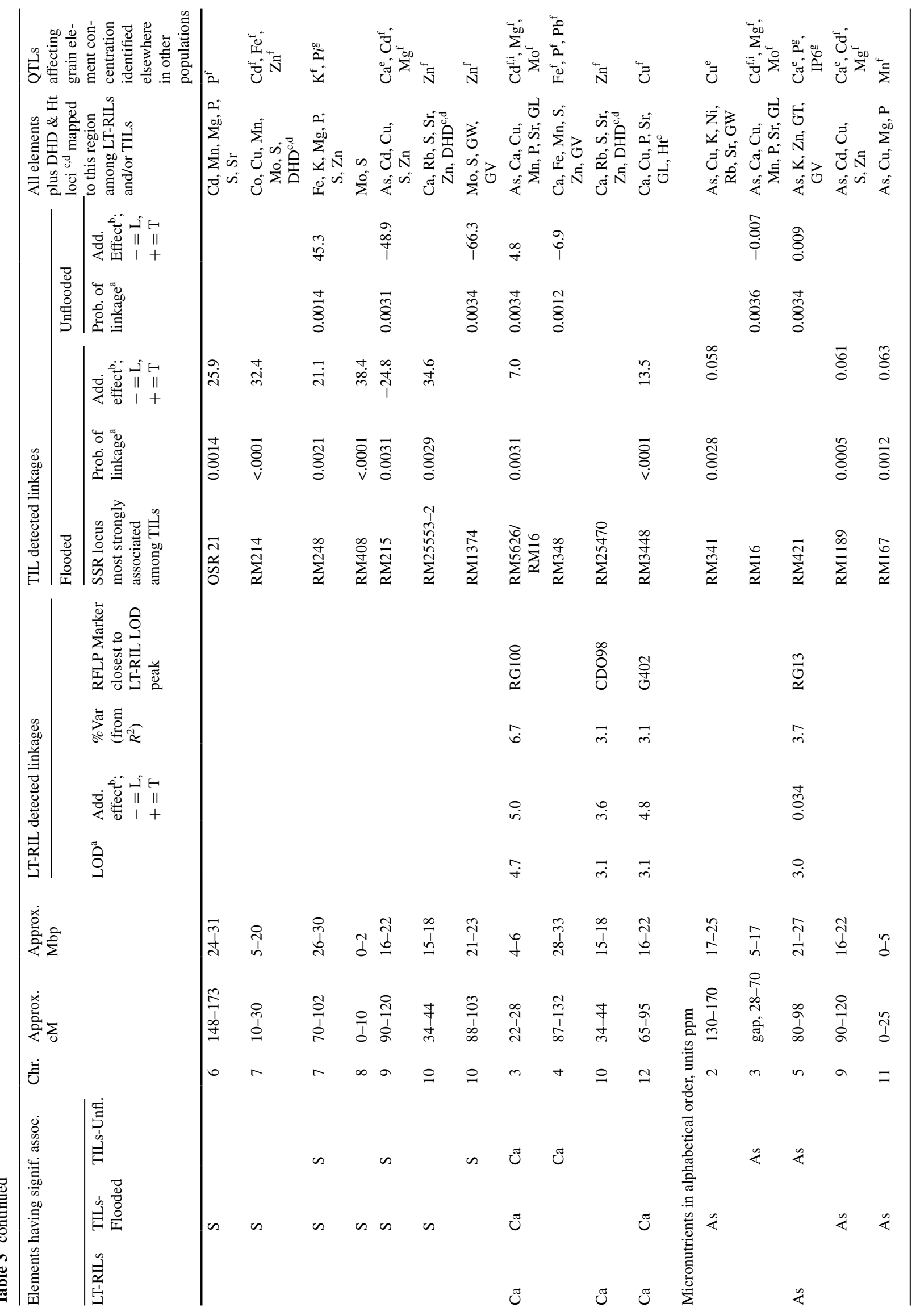




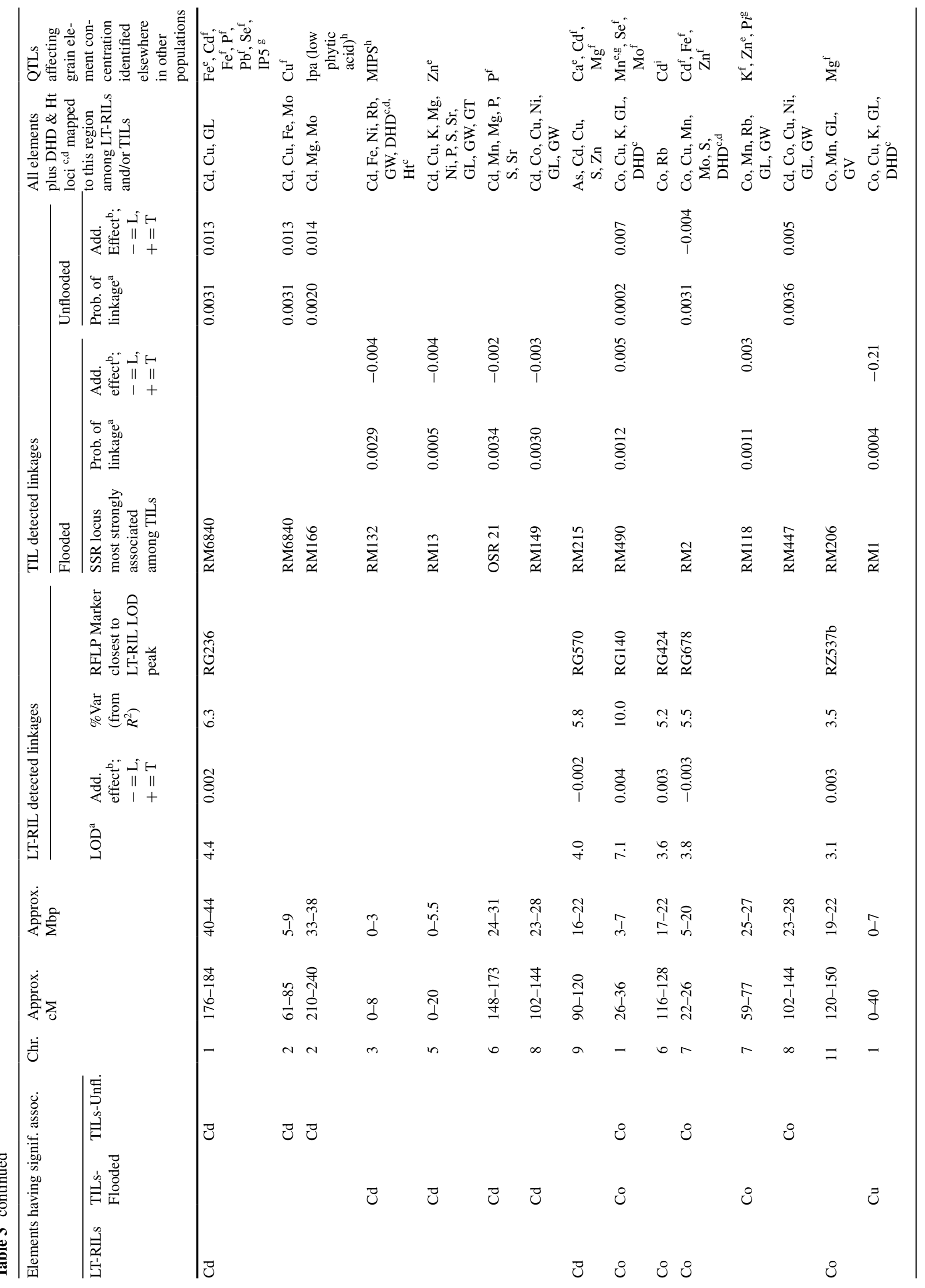




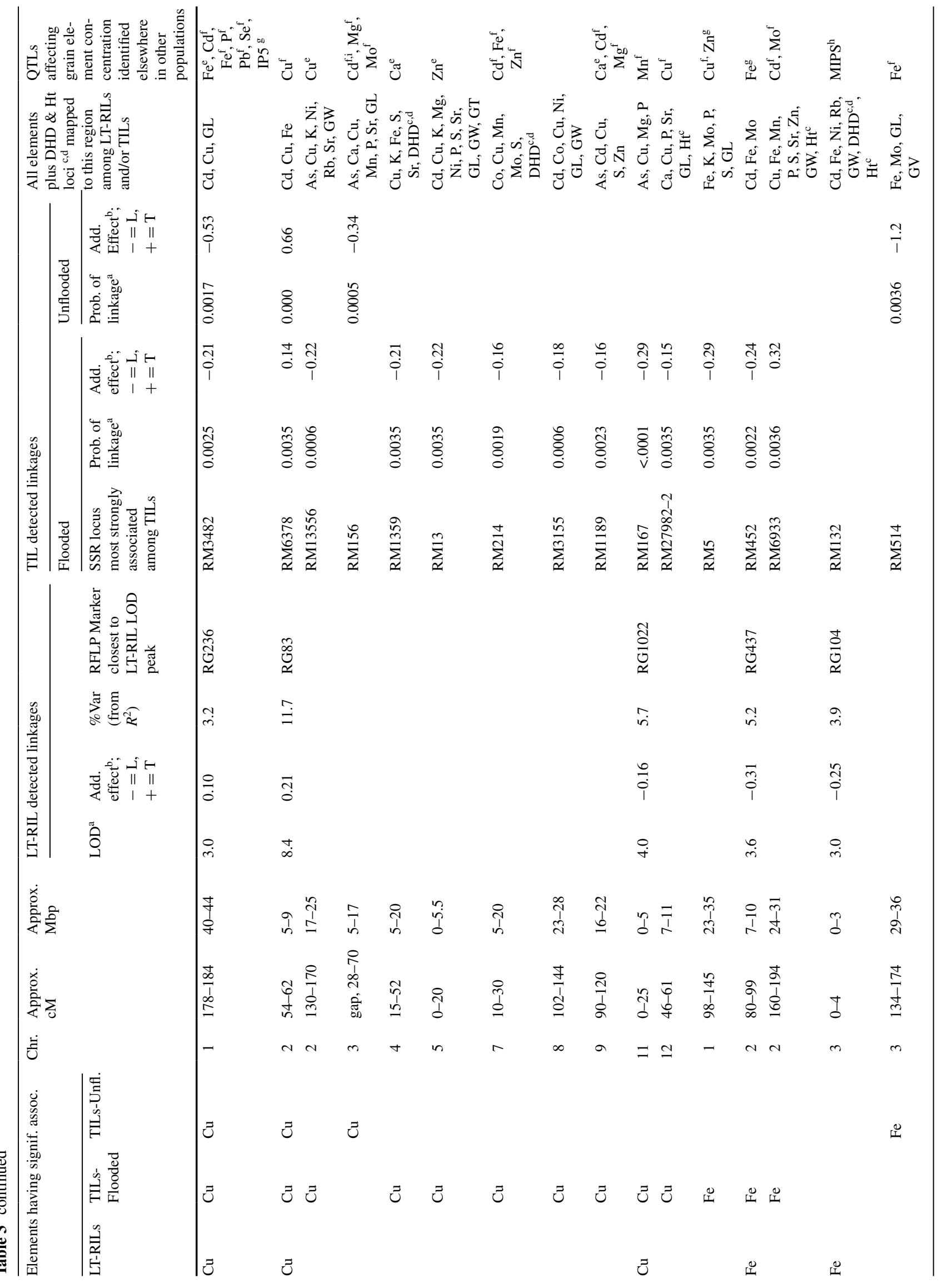




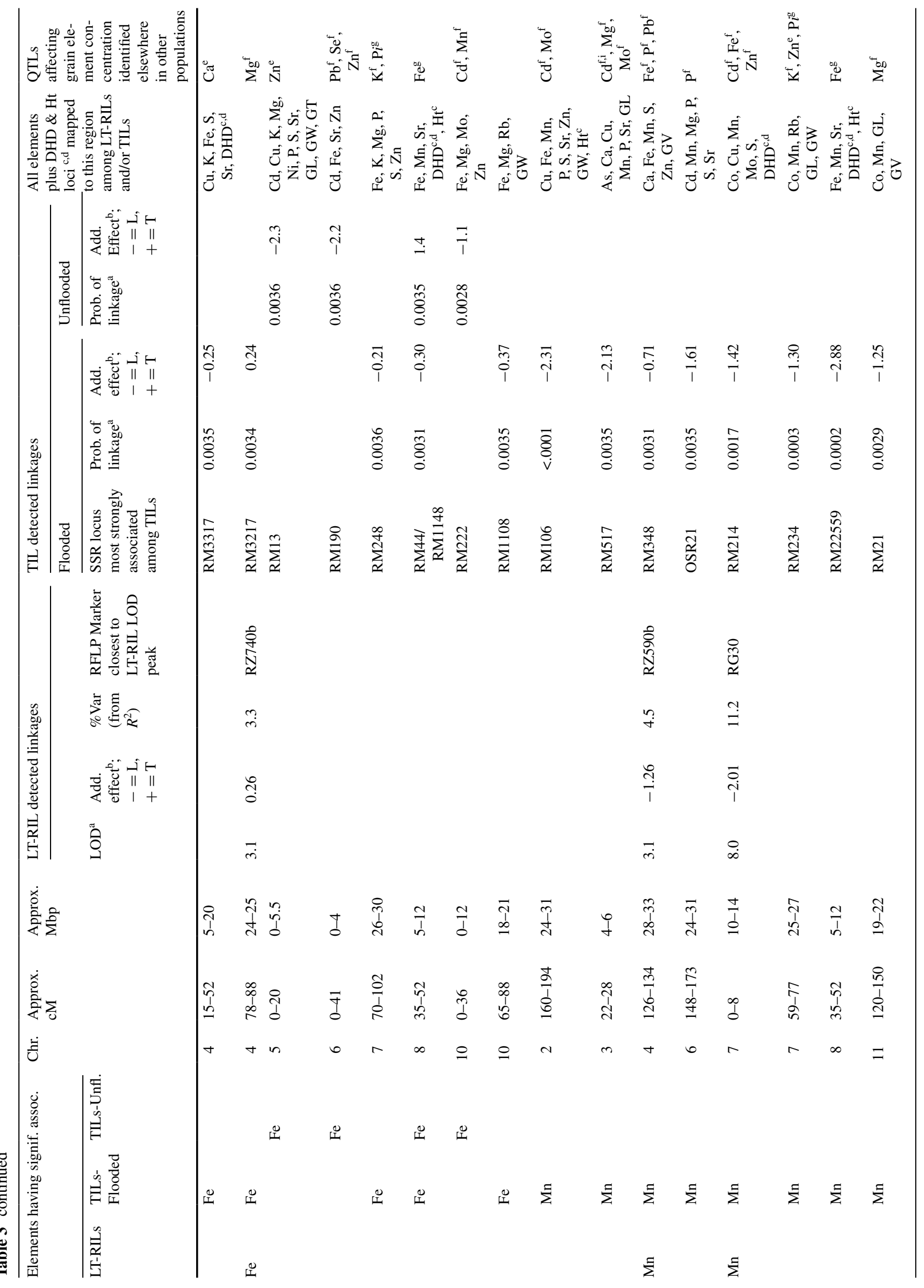




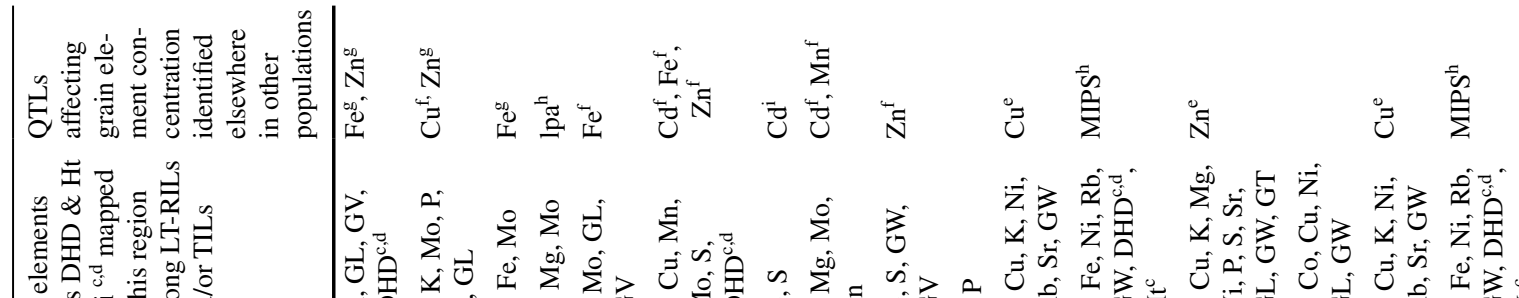

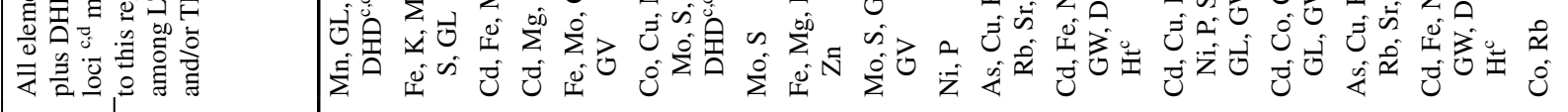

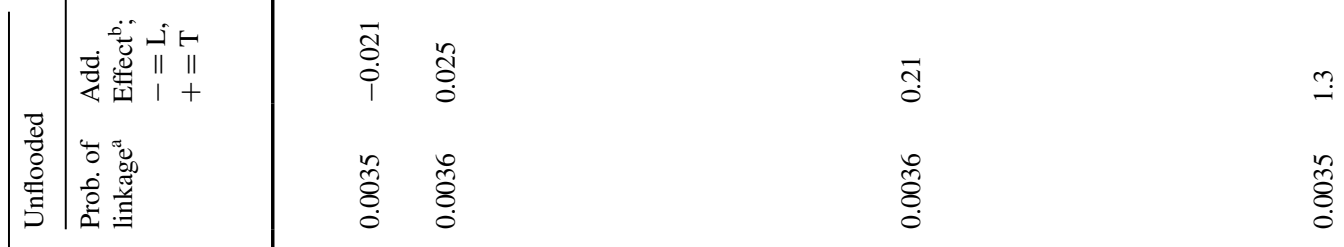

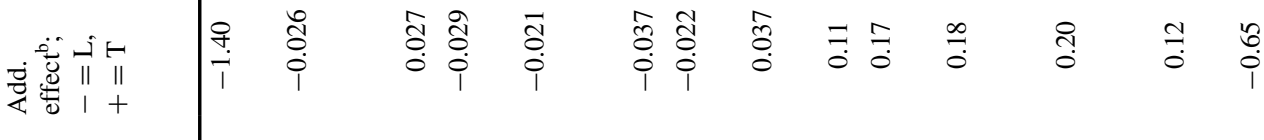

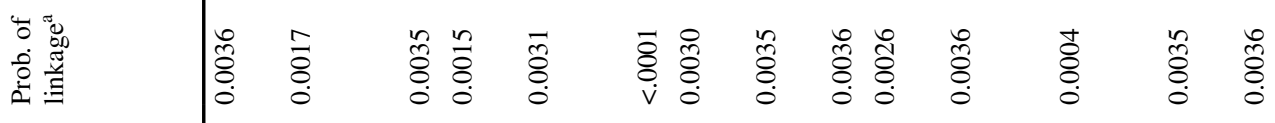

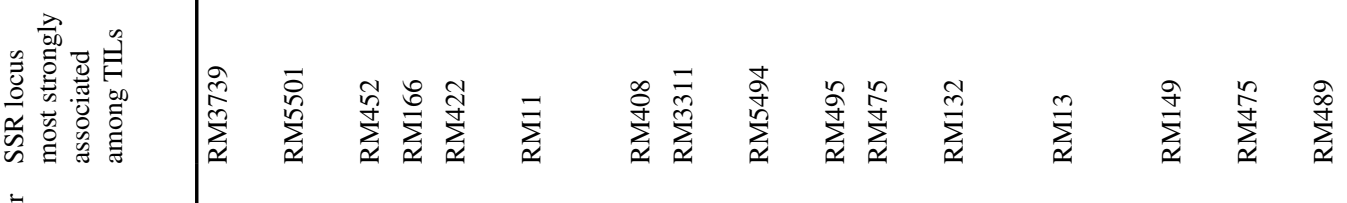

$$
\begin{aligned}
& \text { 离 }
\end{aligned}
$$

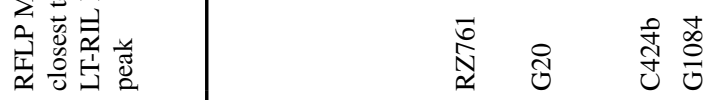

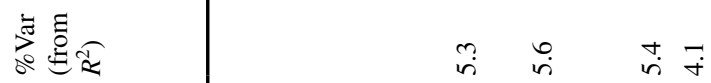

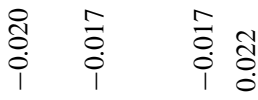

$$
\begin{aligned}
& \dot{m} \quad \vec{m} \quad \vec{m} \ddot{m}
\end{aligned}
$$

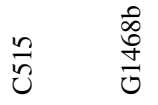

$$
\begin{aligned}
& \stackrel{m}{\stackrel{\sim}{\mathrm{N}}}
\end{aligned}
$$

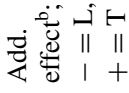

$$
\begin{aligned}
& \text { oิ }
\end{aligned}
$$

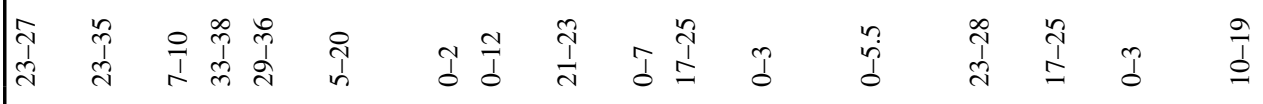

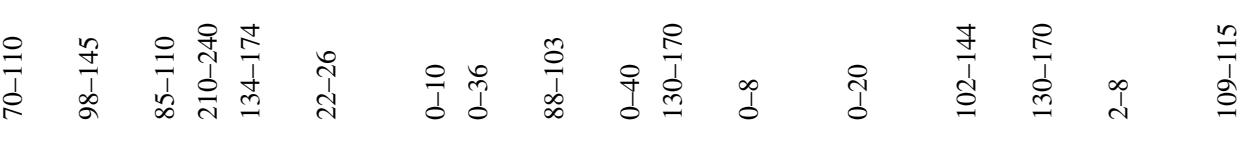

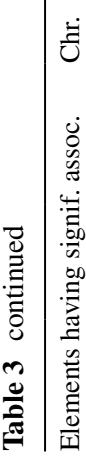

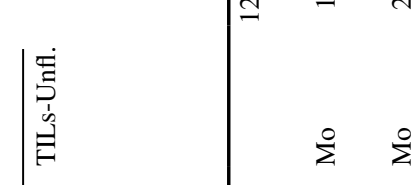

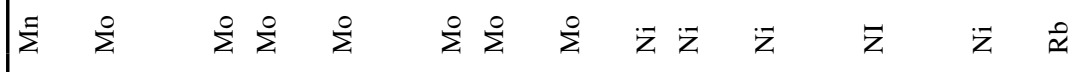

$$
\begin{aligned}
& \stackrel{\circ}{\Sigma} \quad \sum^{\circ} \sum^{\circ} \\
& \text { ะิ ฉิ }
\end{aligned}
$$




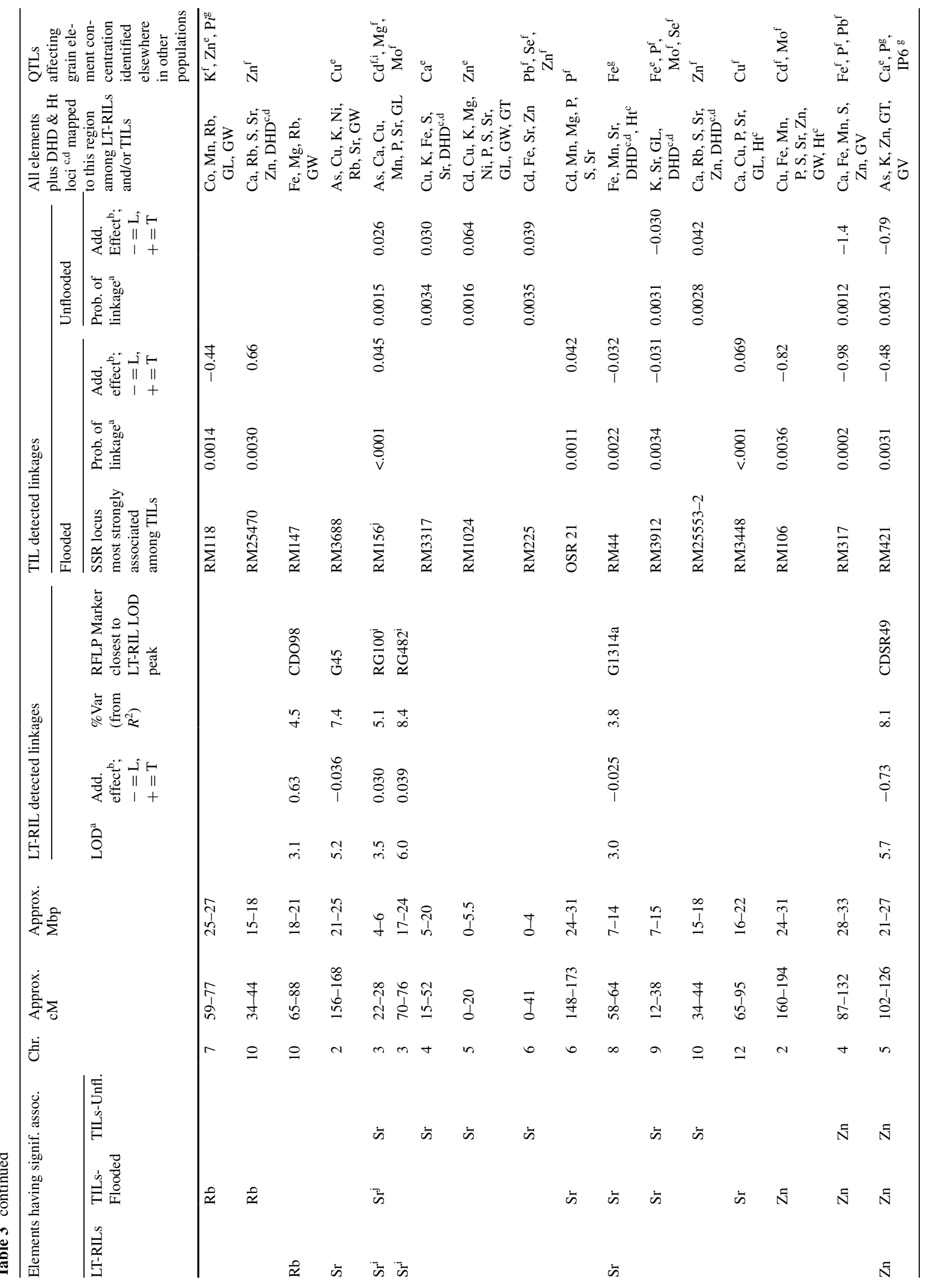




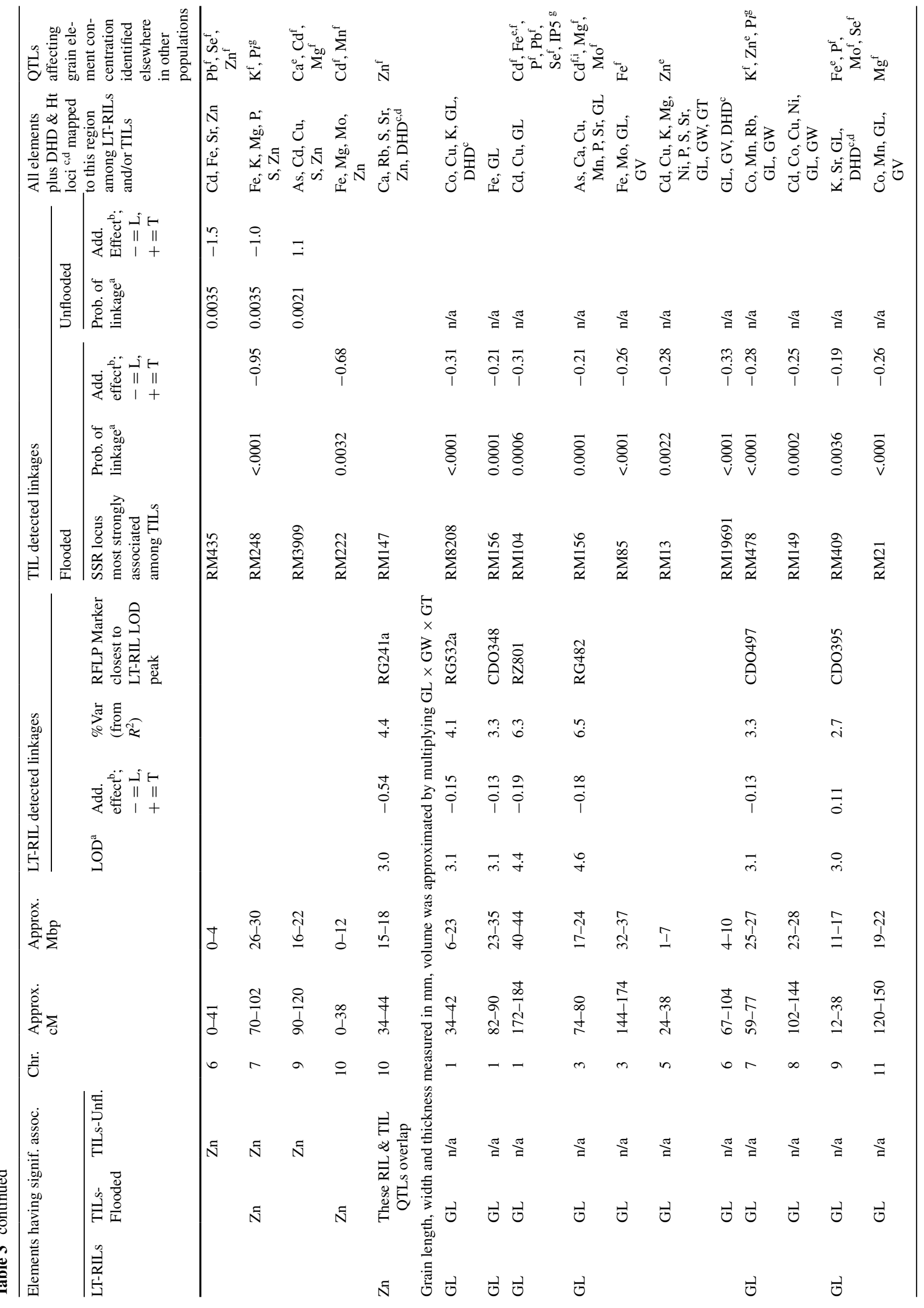




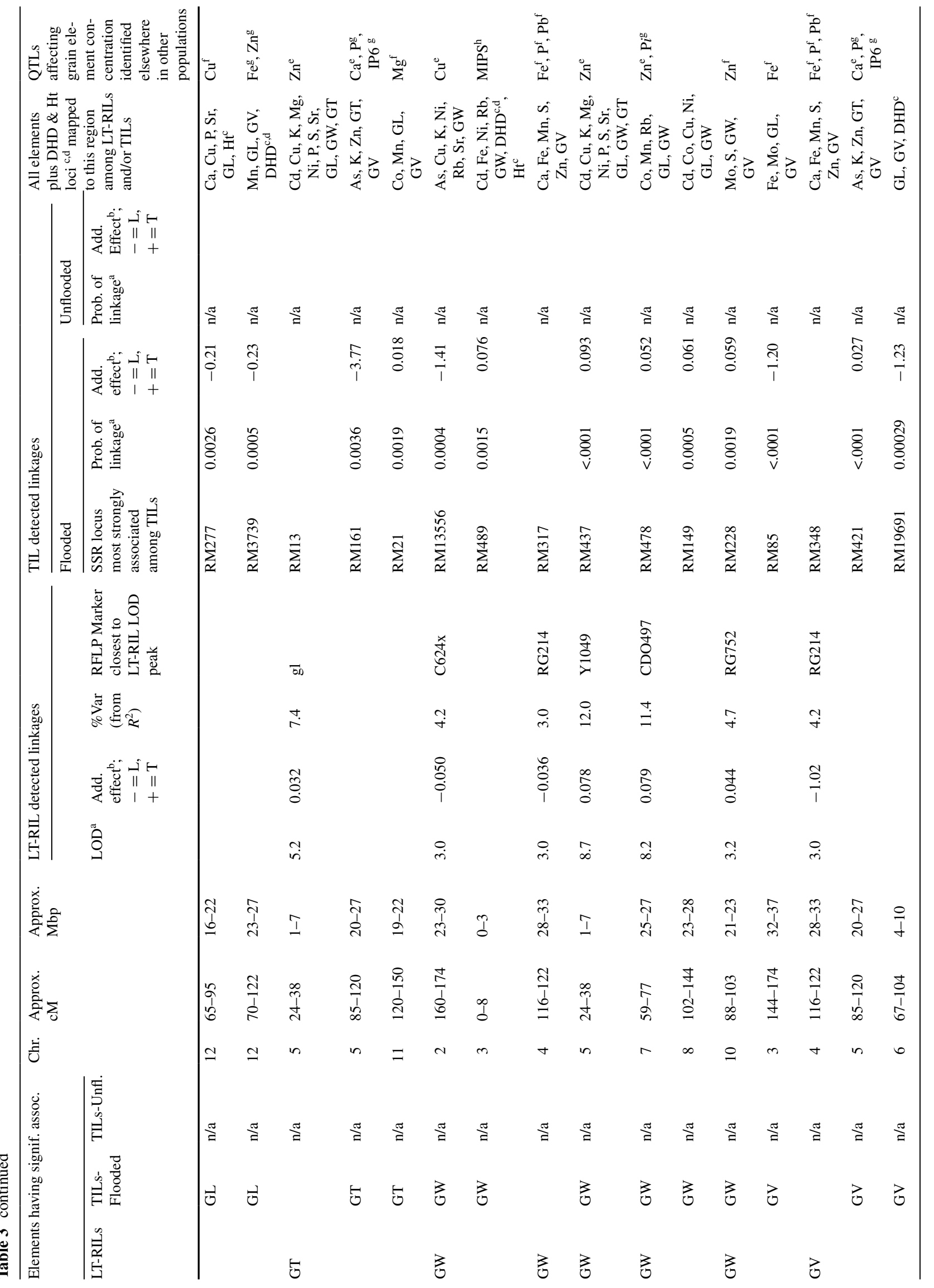




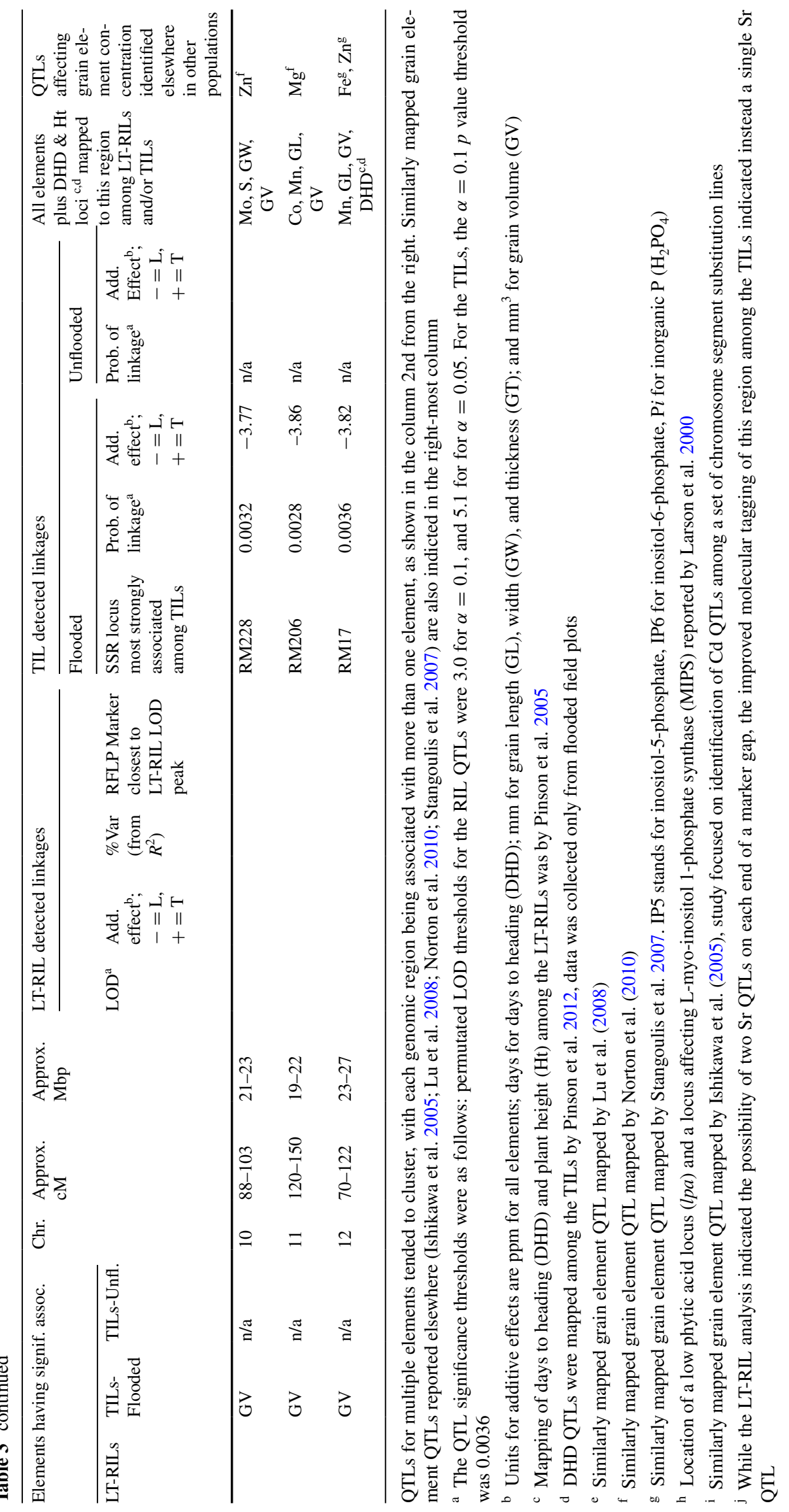



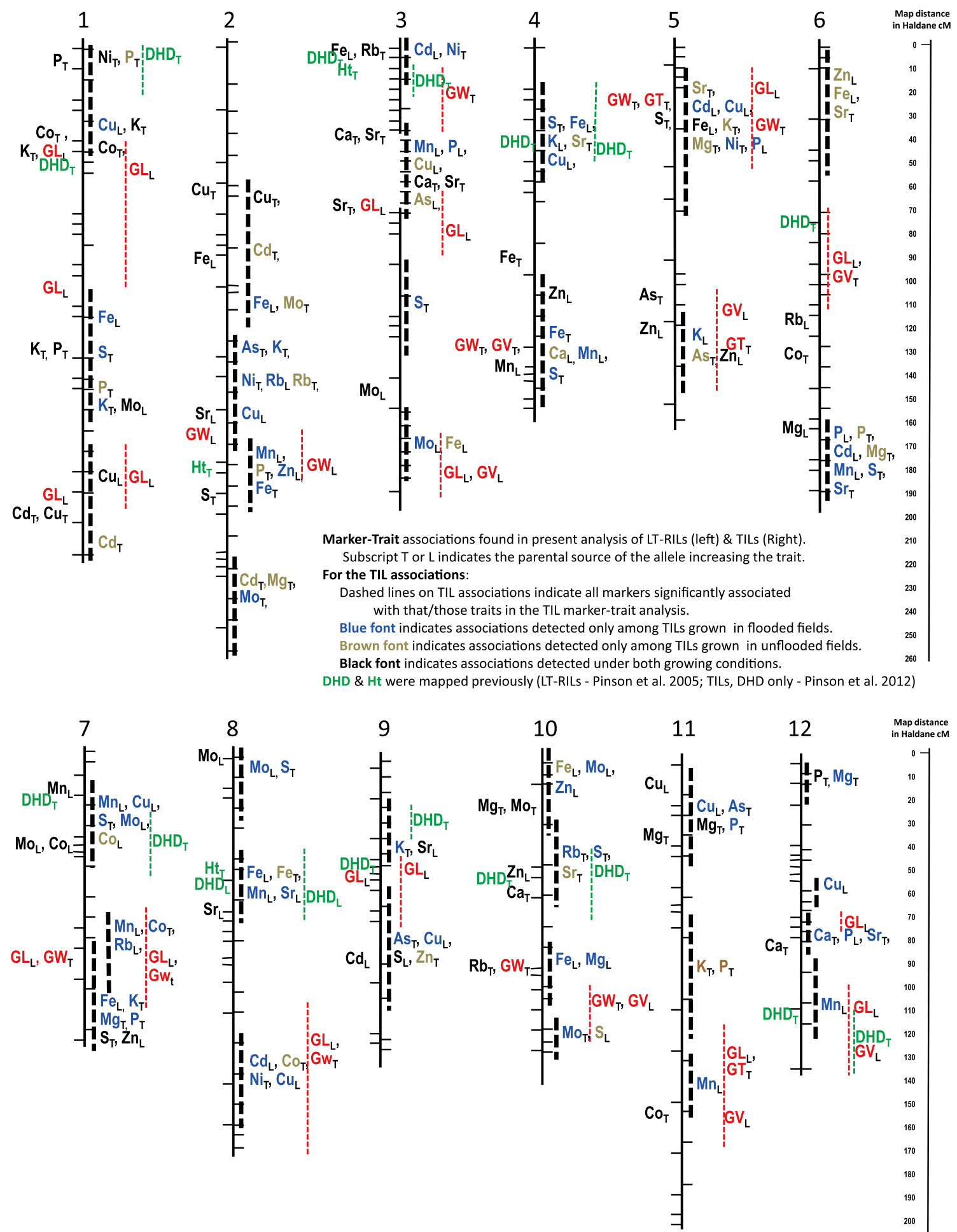

$12 \quad \begin{gathered}\text { Map distance } \\ \text { in Haldane } c \mathrm{M}\end{gathered}$
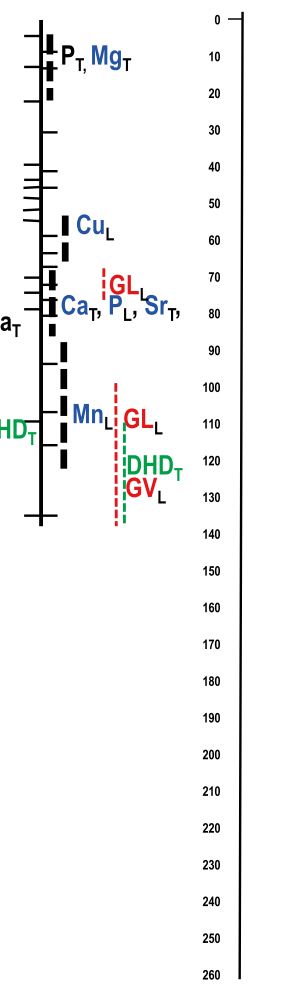
4Fig. 2 A total of 127 QTLs for grain element content were identified among the LT-RIls and the TILs. QTLs found significant among the LT-RILs are indicated to the left of the chromosome lines; QTLs identified among TILs are to the right. QTLs for grain element concentration often clustered in chromosomal regions as diagrammed here, and as indicated in Table 3. QTLs identified for grain shape dimensions are also indicated, as are QTLs for plant height and days to heading, which were determined in prior studies (Pinson et al. 2005, 2012)

conditions (all three population/environment combinations). The estimated additive effects (88, 60 and 88) were fairly consistent across the populations and field environments, and this stable and validated QTL explained $13 \%$ of the phenotypic variance observed among the 5-year LS means of the LT-RILs. This QTL also achieved a significant LOD in all five of the individual year MIM analyses. The stability of this QTL across populations and environments is also indicated in Fig. 2 where it is shown that the TeQing allele was associated with increased grain-K concentration in the LT-RILs, and in the TILs grown under both flooded and unflooded conditions. The TeQing allele of the closely linked Co QTL was also associated with increased grain$\mathrm{Co}$ in all three population/environment conditions. In contrast, the nearby QTL for which the Lemont allele significantly increased grain-Cu among the flooded TILs was not validated in a second population or environment (Fig. 2; Table 3), nor was it validated with identification of a similarly located $\mathrm{Cu}$ QTL reported by others (Table 3).

Additional QTLs that were validated with stable expression across all study populations and environments include a QTL for $\mathrm{Cu}$ located in the 5-7 Mbp (54-62 cM) region of chromosome 2 that explained $12 \%$ of the LT-RIL variance for $\mathrm{Cu}$ and was similarly located with a $\mathrm{Cu}-\mathrm{QTL}$ reported previously by Norton et al. (2010), a QTL affecting both $\mathrm{Ca}$ and $\mathrm{Sr}$ in the 4-20 Mbp region of chromosome 3 that explained 5-8 \% of the LT-RIL variance for these two elements, and a Zn QTL in the lower 21-27 Mbp region of chromosome 5 that explained $8 \%$ of the LT-RIL variance for $\mathrm{Zn}$. The sixth QTL identified in all three populations/ environments was a $\mathrm{Cu}$ QTL in the 40-44 Mbp region of chromosome 1, but curiously, the TeQing allele was found associated with increased grain- $\mathrm{Cu}$ among the LTRILs while the Lemont allele was found associated with increased $\mathrm{Cu}$ among both the flooded and unflooded TILs.

Thirty-three additional QTLs were validated by identification in two of the three study populations/environments. For example, the Mg QTL at the top (0-5 Mbp) of chromosome 11 was found significant among flooded LT-RILs and TILs, but was not significant among unflooded TILs. While this QTL acquired a significant LOD in only two of the two of the five individual LT-RIL years (2002 and 2007), it exhibited a sub-threshold LOD peak in additional years such that the MIM analyses based on LS means calculated across individual planting methods also identified this QTL as statistically significant (LOD > 3.0) in both the staggerplanted and hillplot analyses. While the inability to identify this QTL as significant among unflooded TILs might have been due to increased non-genetic variance among unflooded plots, it could also be related to differences in soil chemistry, root architecture, and/or plant physiology between flooded and unflooded field conditions. At least one QTL per each of the 16 elements was validated in two or more populations/environments. This is true even for $\mathrm{Ni}$, for which no QTLs were identified among the LT-RILs. Among the elements, Mo appeared most stable among years and populations, with $71 \%$ (5 of 7) of its QTLs being found significant in at least two populations/environments.

The phenotypic data used to identify QTLs among the LT-RILs was collected over five field environments, one replication per environment. While high rates of environmental variance within this data would prevent identification of some QTLs, those identified in this manner would be expected to be highly stable. Indeed, a majority $(27 / 40=67 \%)$ of the QTLs identified among the LTRILs based on across-replication LD Means were validated among the TILs. Furthermore, for six elements (As, $\mathrm{Cu}$, Mn, Mo, Sr and Zn) each and every QTL identified among the LT-RILs was identified also among the TILs. It cannot be explained, then, why some QTLs with high significance in one population were not found significant in the other. For example, the Rb QTL identified among the LT-RILs on chromosome 3 with a highly significant 5-year LOD of 8.9, was significant in four of the five individual year LT-RIL MIM analyses, but was not even close to statistically significant among the TILs.

As a corollary to the fact that the flooded TILs identified the most QTLs overall, a lower portion $(31 / 92=34 \%)$ of the QTLs identified among the flooded TILs were also found significant among the LT-RILs (also flooded). Of the 121 specific element QTLs identified among the TILs (either flooded or unflooded or both), 26 (21\%) were verified due to co-location with a QTL for the same element found significant among the LT-RILs, and an additional 10 (8\%) were verified with significance in both the flooded and unflooded TILs, leaving $86(71 \%)$ unverified in the present study. However, when element QTLs reported in the literature are considered (rightmost column of Table 3), another 7 QTLs are verified with identification in two or more populations/environments. For example, the P QTL region on chromosome 7 overlapped with a P QTL reported previously by Stangoulis et al. (2007). Likewise, external but not internal verification exists for one K QTL (chromosome 7, Norton et al. 2010), one Cd QTL (chromosome 9, Norton et al. 2010), two Cu QTLs (chromosomes 2 and 12, Lu et al. 2008 and Norton et al. 2010, respectively), one Fe QTL (chromosome 3, Norton et al. 2010), and one Zn QTL 
(chromosome 6, Norton et al. 2010). Overall, $36 \%$ (43) of the QTLs found significant among the TILs were verified in terms of association with the same element in more than one population or environment.

One concern associated with interpretation of ICP-MS ionomics data is that interference from molecular ionic species generated in the ICP-MS plasma can decrease the accuracy of some element measurements, such as $\mathrm{Ca}$. In contrast, $\mathrm{Sr}$ is measured more reliably by ICP-MS and is known to be a chemical analog to $\mathrm{Ca}$, sharing plant uptake and transport mechanisms and even serving as acceptable substitute in some biochemical processes. Therefore, determination of $\mathrm{Sr}$, a chemical analog of $\mathrm{Ca}$, in the seed samples could prove to be a more reliable indicator of Ca-uptake and transport capabilities than direct observation of Ca. Among the LT-RILs, a Ca QTL mapped to the end of an RFLP gap on chromosome 3, while Sr mapped to both ends of this marker gap, suggesting the possibility of a large Sr QTL actually residing inside the RFLP gap. This is indeed supported by the results of the flooded and unflooded TILs, which indicated that both $\mathrm{Ca}$ and $\mathrm{Sr}$ were most strongly associated with the region between RM5626 and RM16, near the lower end of the LT-RIL RFLP gap. Among both the LT-RILs and the TILs, the TeQing allele at this locus increased $\mathrm{Sr}$ by 0.04 , and increased Ca by $7 \mathrm{ppm}$ (Table 3). If the concept of QTL verification is extended to include co-location of QTLs for different but chemically analogous elements, then the Ca QTL on chromosome 10 can be considered validated by the similarly located $\mathrm{Sr}$ QTL, raising the number of validated Ca QTLs from 2 to 3 (out of 4 total). Similarly, the co-located P and As QTLs on chromosomes 3 and 11 along with the co-located $\mathrm{K}$ and $\mathrm{Rb}$ QTLs on chromosome 2 would also thus be considered confirmed.

QTL regions commonly associated with more than one element

The 134 individual element QTLs were often found linked $(<25 \mathrm{cM})$ or grouped into multi-element clusters as seen in Fig. 2, and noted in Table 3. Clustering of QTLs for multiple elements was especially common among the TILs. For example, LT-RIL analysis detected a single QTL for S in a region of chromosome 5 where TIL analysis detected association with eight elements, though $\mathrm{S}$ was not among them (Table 3; Fig. 2). Using a linkage threshold of $25 \mathrm{cM}$, the 134 QTLs in Fig. 2 merge into approximately 39 clusters or genomic regions (four on chromosome 1, five on chromosome 2, four on chromosome 3 and so on). Further study would be required to determine if co-location of QTLs is due to existence of linked but separate genes, shared regulatory genes, or pleiotropy (one gene affecting multiple phenotypes). However, considering recent reports of element networks within plants (Baxter 2009; Baxter et al. 2008, 2012b), it seems likely that the QTL clusters are sometimes due to a single factor affecting multiple elements. For example, rates of Se uptake have been shown to affect uptake of $\mathrm{Co}$ and $\mathrm{Cu}$ in both pean and wheat plants (Landberg and Greger 1994). This lends support to the present identification both a Co and Cu QTL in the 0-7 Mbp region of chromosome 1 (Table 3, Fig. 2) where a rice Se QTL was previously reported to reside (Norton et al. 2010).

Co-location of QTLs among the highly correlated macronutrients, $\mathrm{Mg}$, $\mathrm{P}$, and $\mathrm{K}$

$\mathrm{Mg}, \mathrm{P}$ and $\mathrm{K}$ do not share uptake mechanisms, are not tightly chemically coupled with respect to soil solution levels in flooded vs. unflooded soil conditions (De Datta 1987), and do not appear connected in a common plant network among vegetative tissues (Baxter et al. 2008; Baxter 2009), yet they were found highly correlated among the grains of LT-RILs and the TILs, whether grown flooded or unflooded. Furthermore, of the 11 QTLs for P (Table 3; Fig. 2), five were also associated with Mg concentration among the LT-RILs and TILs, and another P locus, on chromosome 3, was co-located with a Mg locus reported by Norton et al. (2010). Of the 11 QTLs for P, 4 were co-located with $\mathrm{K}$ loci, and another two were linked with K loci (i.e., different LOD peaks but near each other on the same chromosome). There were two loci associated with all three elements, $\mathrm{P}, \mathrm{Mg}$ and $\mathrm{K}$, one each on chromosomes 5 and 7. These were also the only two loci with a common association with $\mathrm{Mg}$ and $\mathrm{K}$. The nature of these QTLs, however, does not always fit nicely with their expected nature based upon the positive correlations observed among these three elements across the three studies. For example, for the QTL region on chromosome 5, the allele that increased $\mathrm{P}$ decreased $\mathrm{Mg}$ and $\mathrm{K}$. Interestingly, the gene action for the P and Mg QTL located near RM340 and OSR2 1 on chromosome 6 was opposite between the flooded and unflooded TILs, with the Lemont allele being associated with an increase in both $\mathrm{P}$ and $\mathrm{Mg}$ under flooded conditions, but with the TeQing allele being associated with higher $\mathrm{P}$ and $\mathrm{Mg}$ under unflooded conditions.

Co-location of grain element QTLs with grain shape QTLs, but gene action often indicated opposite allelic effects

A sphere has a lower surface to volume ratio than an elongated ovoid shape. Likewise, a rice kernel having a rounder short- or medium-grain shape has a lower bran:endosperm ratio than a long-grained rice. Since the various elements accumulate in different concentrations in different portions of the grain (Hansen et al. 2012; Liang et al. 2008; Lombi et al. 2009) it was hypothesized that some of the observed 
differences in concentration of specific elements in brown (whole) grain might be attributed to differences in grain shape as indicated by GL, GW, GT, and estimated GV. Upon first observation, there does appear to be a correlation between QTLs for grain shape and element concentration with all 20 grain shape loci being located near QTLs for grain element content (Fig. 2; Table 3). Furthermore, chromosomal regions associated with grain shape were more often associated with high numbers of elements. Of the 11 regions found to be associated with five or more elements in the present study, eight also contained QTLs affecting grain length, width, and/or thickness.

However, upon deeper investigation, the gene actions of co-located grain shape and element QTLs were often opposite from that expected if the elemental concentration differences were due solely to a change in grain shape. For example, $\mathrm{K}$ is generally contained in higher concentrations in the outer bran layer than in the rice endosperm (Lombi et al. 2009), suggesting that alleles associated with increased grain length would be associated also with increased grain-K concentration. However, for the region of chromosome 1 near RG532a and RM1 that was associated with $\mathrm{GL}, \mathrm{K}, \mathrm{Cu}$, and $\mathrm{Co}$, the Lemont allele increased grain length but decreased grain-K concentration. Likewise, the chromosomal region further down on chromosome 1 shows correlation with GL, Fe, K, P, and S. Bran is generally considered more concentrated for $\mathrm{Fe}, \mathrm{K}$, and $\mathrm{P}$ than endosperm (Liang et al. 2008; Lombi et al. 2009). The Lemont allele in this region was associated with increased Fe as one would expect from an increased grain length and bran:endosperm ratio, but conversely associated with decreased $\mathrm{K}$ and $\mathrm{P}$. Upon examinations such as these for all regions associated with grain shape and element concentration, it appears that the majority, if not all, of the grain element QTLs detected within the present study cannot be explained solely by association with grain shape, and are thus detecting other mechanisms of element uptake, transport, and/or grain accumulation.

Co-location with heading time previously mapped within the LT-RILs and TILs

Because plants with a longer vegetative phase (later heading dates) have a longer window of opportunity to mine nutrients out of the soil, it raises the question of whether or not late heading is associated with increased grain element concentration. Alternatively, later grain-fill periods generally occur under cooler air and soil/water temperatures, which could also impact root uptake rates, and rates of translocation of elements within plants. As shown in Table 3 and Fig. 2, nine QTLs have been reported for DHD among the LT-RILs (Pinson et al. 2005), and eight among the TILs (Pinson et al. 2012). The two prior DHD studies had seven DHD loci in common, resulting in a total of 10 DHD loci, two on chromosome 1 which are near each other but were mapped to different locations by the LTRILs and TILs, plus one DHD QTL each on chromosomes $3,4,6,7,8,9,10$, and 12. Only one DHD QTL, on chromosome 6, was not associated with any elemental QTLs. In looking for relationships or patterns of correlation between DHD and the 16 elements, we find primarily a lack of consistency or relationship. For example, the DHD QTL at the top of chromosome 1 was associated with P, but since only one of $12 \mathrm{P}$ QTLs was associated also with DHD, there does not appear to be a causative relationship between DHD and P. The element having QTLs most often co-located with DHD QTLs was Sr, with four (out of 10) QTLs linked with DHD QTLs. An increase in Sr was associated with increased DHD in three cases, in one case greater $\mathrm{Sr}$ concentration was associated with decreased DHD, and there were six additional Sr loci not associated with DHD. The two elements having Pearson correlations with DHD $>0.40$ among the LT-RILs (Table 1a) were Ca and $\mathrm{Rb}$. The detection of correlation between DHD and $\mathrm{Rb}$ likely traces to the fact that the Rb QTL having the largest individual effect (explained $12 \%$ of total LT-RIL variation for $\mathrm{Rb}$, Table 3) is located on the top of chromosome 3 where one of the DHD QTLs with largest effect is known to reside (Pinson et al. 2005, 2012). Since Ht also maps to this region, this $\mathrm{Rb}$ QTL probably also underlies the weak correlation ( $r=0.23$, Table 1a) noted among the LT-RILs between $\mathrm{Ht}$ and $\mathrm{Rb}$.

Differences in element accumulation observed under flooded versus unflooded conditions

Soil chemistry and nutrient availability are known to differ between aerobic (oxidized) and anaerobic (chemically reduced) soil conditions, with some elements being more available to plant uptake when they are chemically reduced under anaerobic soil conditions, e.g. Fe and As. Consistent with soil chemistry and nutrient availability predictions, concentrations of As in grains of TILs and parental plots grown under flooded conditions were 10-times higher than seen in rice produced under unflooded conditions (Supplemental Table 1). Contrary to what one would expect based on increased availability of $\mathrm{Fe}$ in soil solution under flooded conditions, grain concentrations were not significantly different between the flooded and unflooded plots (supplemental table 1). Another factor altering nutrient uptake is the fact that rice roots, when grown under flooded conditions, diffuse oxygen which can reoxidize elements in the rhizosphere. Reoxidation of iron in the soil solution causes a coating of ferric hydroxide to form on the rice roots known as an iron plaque. The iron plaques that form on several wetland plant species in addition to rice 
have been shown to affect the uptake of several nutrients, increasing the uptake of some elements (e.g. P, Zhang et al. 1999), but forming a barrier that can decrease plant uptake of others (e.g. Zn, Zhang et al. 1998; Se, Zhou et al. 2007; As, Hu et al. 2005). Furthermore, rice root architecture also differs when plants are grown under flooded as opposed to unflooded conditions, with plants producing more surfacelevel roots under flooded conditions but deeper roots under unflooded growth conditions (Hoshikawa 1989; Uga et al. 2012)

We analyzed seeds of the TIL population grown in both flooded and unflooded hillplots in 2007 and 2008 in order to investigate whether the grain-element QTLs identified under one field condition have similar importance and allelic effects under the contrasting water treatment. In four instances, the parental allele that was associated with increased element uptake under flooded conditions was conversely associated with decreased concentration of that element in grains produced by unflooded TILs: 1) at a QTL for Rb located on chromosome 2, 2) at a QTL for Fe concentration located on chromosome 8,3) at a QTL for $\mathrm{P}$ concentration located on the bottom of chromosome 6, which is co-located with 4) a QTL for Mg on chromosome 6 wherein the Lemont allele was associated with increased $\mathrm{Mg}$ among the LT-RILs, grown under flooded conditions, while the TeQing allele was associated with increased $\mathrm{Mg}$ among the TILs grown unflooded, but was not found significantly associated among the flood-produced TILs (Table 3; Fig. 2). These instances of altered gene action observed under flooded and unflooded growing conditions, while rare among the presently identified grain element QTLs, do suggest the importance of controlling soil saturation levels when conducting ionomic studies.

\section{Discussion}

The correlations noted between the grain elemental concentrations are of interest because they suggest the possibility of shared mechanisms/genes for root uptake and/or transport to rice grains. For example, although $\mathrm{Sr}$ is not essential to plants, it is taken up by plants because it is a chemical analog of $\mathrm{Ca}$. Therefore, the fact that $\mathrm{Sr}$ and $\mathrm{Ca}$ were highly correlated under both flooded and unflooded conditions ( $r$ ranged 0.52-0.66, Table 1) was as anticipated. In contrast, $\mathrm{Mg}, \mathrm{P}$, and $\mathrm{K}$ each have different mechanisms of root uptake and transport within plants, and yet were so highly correlated ( $r$ ranged $0.44-0.91$ ) with each other across both populations and water-management treatments (Table 3), that their correlations with the other 13 elements also tended to be similar in both magnitude and sign (positive or negative). Elements that were typically negatively (or not significantly) correlated with $\mathrm{Mg}, \mathrm{P}$, and $\mathrm{K}$ among the
LT-RILs and TILs, under both flooded and unflooded growing conditions were $\mathrm{Ca}, \mathrm{Sr}, \mathrm{Fe}, \mathrm{Cu}$ and $\mathrm{Zn}$, while $\mathrm{Rb}$ and $\mathrm{Cd}$ were predominantly positively correlated. The relationship between some elements reversed sign depending on whether the seed was produced under flooded or unflooded conditions. Specifically, S and Ni were negatively (or not significantly) correlated with the $\mathrm{Mg}-\mathrm{P}-\mathrm{K}$ complex among both the LT-RILs and the TILs when grown under flooded conditions but were positively correlated when grown unflooded, while As and Co were positively correlated with $\mathrm{Mg}-\mathrm{P}-\mathrm{K}$ under flooded conditions, but negatively correlated in seed from unflooded field conditions.

Strong correlations among $\mathrm{P}, \mathrm{Mg}$ and $\mathrm{K}$ have also been reported in seeds of $A$. thaliana (Baxter et al. 2008; Vreugdenhil et al. 2004) and maize (Baxter et al. 2012a). In rice, as in many cereal grains (Bryant et al. 2005), most of the seed phosphorus is found in the form of a mixed $\mathrm{K} / \mathrm{Mg}$ salt of phytic acid in the germ and aleurone layer, so one possible explanation of the positive $\mathrm{P}-\mathrm{Mg}-\mathrm{K}$ correlations might be that they are all driven by phytate levels in the grain. Vreugdenhil et al. (2004) found co-localization of QTL for K and Ca with a high P/high phytate locus in Arabidopsis suggesting that phytate levels were affecting $\mathrm{P}-\mathrm{K}$ associations. However, a phytate-less mutant of rice did not display altered total grain P concentration (Bryant et al. 2005), suggesting that something other than phytate levels in the bran is controlling total grain accumulation of $\mathrm{P}$.

From the present study, 134 QTLs associated with the concentration of individual elements in rice grains were found clustered in 39 chromosomal regions, suggesting the importance of considering grain ionomes and element networks rather than focusing future studies on one or few targeted elements. The interconnectedness observed between the elements also indicates the importance of conducting ionomics studies under conditions that minimize withinstudy variance for factors affecting soil fertility such as soil moisture, soil texture, content of organic matter, and soil temperature. Even small irregularities or dips in soil surface level may cause moisture and nutrients to pool, causing micro-environmental variance in nutrient availability between two nearby plants.

More QTLs achieved statistical significance in the analysis of flooded TILs than in the analysis of LT-RILs or unflooded TILs. This may be, in part, due to the fact that the more homogenous genetic background among the TILs enhances ability to detect QTLs of smaller individual effect. Additionally, three of the five LT-RIL replications involved plots grown over a wide field area, likely subjecting them to increased within-study variance for soil fertility. An increase in environmentally induced variance for grain element concentration would result in decreased ability to detect grain element QTLs of smaller effect among 
the LT-RILs. Field flooding increases spread of soil nutrients from one point in the field to another [with the relatively increased hydraulic conductivity of the saturated soil (Hillel 1980)], decreasing micro-environmental effects. This may be why more QTLs were detected among the flooded TILs than among the unflooded TILs.

Grain shape, heading time, and plant height could all potentially induce differences in element concentrations observed among whole (unmilled) grains. Many of the elemental QTLs, even when co-located with QTLs for grain shape, $\mathrm{HD}$, or $\mathrm{Ht}$, did not differ as predicted if the grain elemental concentration differences were caused solely by these other traits. This suggests that those grain element QTLs have an underlying cause that is different from, and stronger than, the predicted shape, HD, or Ht effects.

Mapping the grain element QTLs in the LT-RILs and TILs made it possible to readily compare the location of the newly identified grain element QTLs with those of several agronomic traits. Most of the previous LT-RIL and TIL gene-mapping efforts targeted the identification of loci associated with disease resistance. The locations were thus known for several loci conferring resistance to rice sheath blight disease (Pinson et al. 2005), rice blast disease (Tabien et al. 2000, 2002), bacterial leaf blight (Li et al. 1999a), and bacterial panicle blight (Pinson et al. 2010). Interestingly, the disease resistance loci themselves were often clustered or co-located (Pinson et al. 2010). When the locations of the previously mapped disease resistance QTLs were compared to the newly identified grain ionomic QTLs, an association between $\mathrm{Ca}, \mathrm{Sr}$ and disease resistance was indicated. Of the 11 QTLs associated with $\mathrm{Ca}$ and/or its chemical analog, $\mathrm{Sr}, 10$ had mapped to genomic regions known to contain loci affecting resistance to one or multiple rice diseases. The sole Sr locus not associated with disease resistance was located on the upper end of chromosome 6, and was detected among unflooded TILs but not among the flooded LT-RILs and TILs, leaving this QTL region unverified. It is known that $\mathrm{Ca}$ increases strength of cell walls and membranes (for review of $\mathrm{Ca}$ in plants, see Hepler 2005), and thus may contribute to quantitative disease resistance by slowing infection rates. It is also known that $\mathrm{Ca}$ plays a role in the cell-to-cell signaling critical to the hypersensitive necrosis that provides resistance to rice blast disease and rice bacterial blight disease (Kuta and Gaivaronskaya 2004).

In summary, QTLs are here reported for concentrations of 16 elements (ionome) in rice grain. Two mapping populations, the LT-RIL and the TIL (which was grown both flooded and unflooded), were used in the study so that putative QTLs could be identified in one, and verified in the other. This constitutes the first report of grain ionomic QTLs identified in seed produced under unflooded field conditions. Transgressive segregation was observed in the LT-RIL population for all 16 elements. A number of interesting patterns were found among the correlations between elements deserving of additional study to understand their bases. These include a $\mathrm{Ca}$ and $\mathrm{Sr}$ association that was largely supported by the QTL associations and a strong $\mathrm{Mg}-\mathrm{P}-\mathrm{K}$ complex. The QTLs also showed interesting patterns deserving additional study. For example, the elemental QTLs tended to cluster into genomic regions (134 QTLs into 39 regions) often with multiple elements associated with a region, lending support to the concept of ionomic networks. This further suggests that, when studying grain nutritional value, it is important to study multiple elements at a time, and to carefully control factors such as soil fertility, temperature, and $\mathrm{pH}$ that can affect uptake the ability of plants to take nutrients in from the soil. More QTLs and element-to-element correlations were identified among the flooded TILs than the unflooded TILs, hinting that less microenvironmental variability might exist under flooded conditions. Several plant characteristics, namely grain shape, heading time and plant height, had much less direct influence on rice grain mineral concentrations based on the QTL associations than was anticipated. In addition, a strong association of $\mathrm{Ca} / \mathrm{Sr}$ QTLs with disease resistance loci was noted.

Acknowledgments This research was supported in part by the US National Science Foundation, Plant Genome Research Program (Grant \#IOS 0701119) awarded to D.E.S, M.L.G and S.R.M.P. We acknowledge Dr. Kathleen Yeater for consultation on analyzing marker-trait associations using SAS JMP Genomics. Mention of a trademark or proprietary product does not constitute a guarantee or warranty of the product by the US Department of Agriculture or Texas A\&M AgriLife Research, and does not imply its approval to the exclusion of other products that also can be suitable. USDA is an equal opportunity provider and employer.

Conflict of interest The authors declare that they have no conflict of interest.

Ethical standards All experiments complied with the current laws of the USA, the country in which they were performed.

Open Access This article is distributed under the terms of the Creative Commons Attribution License which permits any use, distribution, and reproduction in any medium, provided the original author(s) and the source are credited.

\section{References}

Abdi H (2007) The Bonferroni and Šidák corrections for multiple comparisons. In: Salkind NJ (ed) Encyclopedia of measurement and statistics. Sage Publications, Thousand Oaks, pp. 103-107. http://www.utdallas.edu/ herve/Abdi-Bonferroni2007-pretty.pdf

Arao T, Kawasaki A, Baba K, More S, Matsumoto S (2009) Effects of water management on cadmium and arsenic accumulation and dimethylarsinic acid concentrations in Japanese rice. Environ Sci Technol 43:9361-9367 
Baxter IR (2009) Ionomics: studying the social network of mineral nutrients. Curr Opin Plant Biol 12:381-386

Baxter IR, Vitek O, Lahner B, Muthukumar B, Borghi M, Morrissey J, Guerinot ML, Salt DE (2008) The leaf ionome as multivariable system to detect a plant's physiological status. Proc Natl Acad Sci USA 105:12081-12086

Baxter IR, Gustin JL, Settles AM, Hoekenga OA (2012a) Ionomic characterization of maize kernels in the intermated B73 $\times$ Mo17 population. Crop Sci 53:208-220

Baxter IR, Hermans C, Lahner B, Yakubova E, Tikhonova M et al (2012b) Biodiversity of mineral nutrient and trace element accumulation in Arabidopsis thaliana. PLoS ONE 7:e35121

Benjamini Y, Hochberg Y (1995) Controlling the false discovery rate: a practical and powerful approach to multiple testing. J Royal Stat Soc. Ser. B (Methodol) 57:289-300

Bentsink L, Yuan K, Koornneef M, Vreugdenhil D (2003) The genetics of phytate and phosphate accumulation in seeds and leaves of Arabidopsis thaliana, using natural variation. Theor Appl Genet 106:1234-1243

Bryant RJ, Dot'sch JA, Peterson KL, Rutger JN, Raboy V (2005) Phosphorus and mineral concentrations in whole grain and milled low phytic acid (lpa)1-1 rice. Cereal Chem 82:517-522

Daum D, Bogdan K, Schenk MK, Merkel D (2002) Influence of the field water management on accumulation of arsenic and cadmium in paddy rice. Dev Plant Soil Sci 92:290-291

De Datta SK (1987) Principles and practices of rice production. Robert Krieger Publishing Co., Malabar

Dong MH, Sang DZ, Wang P, Wang XM, Yang JC (2007) Changes in cooking and nutrition qualities of grains at different postions in a rice panicle under different nitrogen levels. Rice Sci 14: $141-148$

Grusak MA, Pomper KW (1999) Influence of pod stomatal density and pod transpiration on the calcium concentration of snap bean pods. J Am Soc Hort Sci 124:194-198

Hansen TH, Lombi E, Fitzgerald M, Laursen KH, Frydenvang J, Husted S, Boualaphanh D, Resurreccion A, Howard DL, de Jonge MD, Paterson D, Schjoerring JK (2012) Losses of essential mineral nutrients by polishing of rice differ among genotypes due to contrasting grain hardness and mineral distribution. J Cereal Sci 56:307-315

Harris N, Juliano BO (1977) Ultrastructue of endosperm protein bodies in developing rice grains differing in protein content. Ann Bot 41:1-5

Hepler PK (2005) Calcium: a central regulator of plant growth and development. Plant Cell 17:2142-2155

Hillel D (1980) Flow of water in saturated soil. In: Hillel D (ed) Fundamentals of soil physics. Acad. Press, New York, pp 166-194

Hoshikawa K (1989) The growing rice plant: an anatomical monograph. Nobunkyo, Tokyo

Hu Y, Li J-H, Zhu Y-G, Huang Y-Z, Hu H-Q, Christie P (2005) Sequestration of As by iron plaque on the roots of three rice (Oryza sativa L.) cultivars in a low-P soil with or without $\mathrm{P}$ fertilizer. Environ Geochem Health 27:169-176. doi:10.1007/ s10653-005-0132-5

Ishikawa S, Ae N, Yano M (2005) Chromosomal regions with quantitative trait loci controlling cadmium concentration in brown rice (Oryza sativa). New Phytol 168:345-350

Joehanes R, Nelson JC (2008) QGene 4.0, an extensible Java QTL analysis platform. Bioinformatics 24:2788-2789

Kao C-H, Zeng Z-B, Teasdale RD (1999) Multiple interval mapping for quantitative trait loci. Genetics 152:1203-1216

Kuramata M, Abe T, Kawasaki A, Ebana K, Shibaya T, Yano M, Ishikawa S (2013) Genetic diversity of arsenic accumulation in rice and QTL analysis of methylated arsenic in rice grains. Rice 6:3. doi:10.1186/1939-8433-6-3
Kuta DD, Gaivaronskaya LM (2004) $\mathrm{Ca}^{2+}$ and reactive oxygen species are involved in the defense responses of rice callus culture to rice blast disease. African J Biotechnol 3:76-81

Landberg T, Greger M (1994) Influence of selenium on uptake and toxicity of copper and cadmium in pea (Pisum sativum) and wheat (Triticum aestivum). Physiol Plant 90:637-644

Larson SR, Rutger JN, Young KA, Raboy V (2000) Isolation and genetic mapping of a non-lethal rice (Oryza sativa L.) low phytic acid 1 mutation. Crop Sci 40:1397-1405

Li Z, Pinson SRM, Stansel JW, Park WD (1995) Identification of quantitative trait loci (QTLs) for heading date and plant height in cultivated rice (Oryza sativa L.). Theor Appl Gen 91:374-381

Li Z, Pinson SRM, Park WD, Paterson AH, Stansel JW (1997) Epistasis for three grain yield components in rice (Oryza sativa L.). Genetics 145:453-465

Li Z, Pinson SRM, Stansel JW, Paterson AH (1998) Genetic dissection of the source-sink relationship affecting fecundity and yield in rice (Oryza sativa L.). Mol Breed 4:419-426

Li Z, Luo LJ, Mei HW, Paterson AH, Zhao XH, Zhong DB, Wang YP, Yu XQ, Zhu L, Tabien RE, Stansel JW, Ying CS (1999a) A "defeated" rice resistance gene acts as a QTL against a virulent strain of Xanthomonas oryzae pv oryzae. Mol Gen Genet 261:58-63

Li Z, Paterson AH, Pinson SRM, Stansel JW (1999b) RFLP facilitated analysis of tiller and leaf angles in rice (Oryza sativa L.). Euphytica 109:79-84

Liang J, Li Z, Tsuji K, Nakano K, Nout MJR, Hamer RJ (2008) Milling characteristics and distribution of phytic acid and zinc in long-, medium- and short-grain rice. J Cer Sci 48:83-91

Liu ZH, Cheng FM, Cheng WD, Zhang GP (2005) Positional variations in phytic acid and protein content within a panicle of japonica rice. J Cereal Sci 41:297-303

Lombi E, Scheckel KG, Pallon J, Carey AM, Zhu YG, Meharg AA (2009) Speciation and distribution of arsenic and localization of nutrients in rice grains. New Phytol 184:193-201

Lu K, Li L, Zheng X, Zhang Z, Mou T, Hu Z (2008) Quantitative trait loci controlling $\mathrm{Cu}, \mathrm{Ca}, \mathrm{Zn}, \mathrm{Mn}$ and $\mathrm{Fe}$ content in rice grains. $\mathrm{J}$ Genetics 87:305-310

Mei HW, Li ZK, Shu QY, Guo LB, Wang YP, Yu XQ, Ying CS, Luo LJ (2005) Gene actions of QTLs affecting several agronomic traits resolved in a recombinant inbred rice population and two backcross populations. Theor Appl Genet 110:649-659

Nagelkerke NJD (1991) A note on a general definition of the coefficient of determination. Biometrika 78:691-692

Norton GJ, Deacon CM, Xiong L, Huang S, Meharg AA, Price AH (2010) Genetic mapping of the rice ionome in leaves and grain: identification of QTLs for 17 elements including arsenic, cadmium, iron and selenium. Plant Soil 329:139-153

Parengam M, Judprasong K, Srianujata S, Jittinandana S, Laoharojanaphand S, Busamongko A (2010) Study of nutrients and toxic minerals in rice and legumes by instrumental neutron activation analysis and graphite furnace atomic absorption spectrophotomerty. J Food Comp Anal 23:340-345

Patrick WH Jr, Khalid RA (1974) Phosphate release and sorption by soils and sediments: effect of aerobic and anaerobic conditions. Science 186:53-55

Patrick WH Jr., Jugsujinda A (1986) Redox and pH chemistry and nutrient uptake by rice in flooded oxisols of Sitiung Area of Sumatra, Indonesia. A Technical Report No. 1 USAID Grant No. DPE-5542-G-SS-4055-00 (3.F-10). http://pdf.usaid.gov/pdf_ docs/PNABP482.pdf. Accessed 31 May 2012

Pinson SRM, Capdevielle FM, Oard JH (2005) Confirming QTLs and finding additional loci conditioning sheath blight resistance in rice using recombinant inbred lines. Crop Sci 45:503-510

Pinson SRM, Shahjahan AKM, Rush MC, Groth DE (2010) Bacterial panicle blight resistance QTLs in rice (Oryza sativa L.) and their 
association with heading date and other disease resistance loci. Crop Sci 50:1287-1297

Pinson SRM, Liu G, Jia MH, Jia Y, Fjellstrom RG, Sharma A, Wang Y, Tabien RE, Li ZK (2012) Registration of a rice gene mapping population consisting of 'TeQing'-into- 'Lemont' (TIL) backcross introgression lines. J Plant Reg 6:128-135

Quintana JM, Harrison HC, Palta JP, Nienhuis J, Kmiecik K (1999) Xylem flow rate differences are associated with genetic variation in snap bean pod calcium concentration. J Am Soc Hort Sci 124:488-491

Resurreccion AP, Hara T, Juliano BO, Yoshida S (1977) Effect of temperature during ripening on grain quality of rice. Soil Sci Plant Nutr 23:109-112

Samonte SOPB, Wilson LT, Tabien RE (2005) Maximum node production rate and main culm node number contributions to yield and yield-related traits in rice. Field Crops Res 96:313-314

SAS Institute (2007) SAS 9.1.3 help and documentation. SAS Institute Inc, Cary

SAS Institute (2009) JMP/Genomics 4.0 help and documentation. SAS Institute Inc, Cary

SAS Institute (2010) JMP 9.0 basic analysis and graphing. SAS Institute Inc, Cary

Stangoulis J (2010) Technical aspects of zinc and iron analysis in biofortification of the staple food crops, wheat and rice. 19th World Congress of Soil Science, Soil Solutions for a Changing World. 1-6 August 2010, Brisbane, Australia. Published on DVD. http://www.dfid.gov.uk/r4d/PDF/Outputs/Misc_Crop/Stangoulis2499.pdf. Accessed 31 May 2013

Stangoulis JC, Huynh B-L, Welch RM, Choi E-Y, Graham RD (2007) Quantitative trait loci for phytate in rice grain and their relationship with grain micronutrient content. Euphytica 154:289-294

Steffens B, Geske T, Sauter M (2011) Aerenchyma formation in the rice stem and its promotion by $\mathrm{H}_{2} \mathrm{O}_{2}$. New Phytol 190:369-378

Tabien RE, Li Z-K, Paterson AH, Marchetti MA, Stansel JW, Pinson SRM (2000) Mapping of four major blast resistance genes from $>$ Lemont $=$ and $>$ TeQing $=$ and evaluation of the combinatorial effect for field resistance. Theor Appl Genet 101:1215-1225

Tabien RE, Li Z-K, Paterson AH, Marchetti MA, Stansel JW, Pinson SRM (2002) Mapping QTL for field resistance to the rice blast pathogen and evaluating their individual and combined utility in improved varieties. Theor Appl Genet 105:313-324

Tani FH, Barrington S (2005) Zinc and copper uptake by plants under two transpiration rates. Part I. Wheat (Triticum aestivum L.). Environ Pollut 138:538-547

Tong H-H, Mei H-W, Yu X-Q, Zu X-Y, Li M-S, Zhang S-Q, Luo L-J (2006) Identification of related QTLs at late developmental stage in rice (Oryza sativa L.) under two nitrogen levels. Acta Genet Sin 33:458-467
Uga Y, Hanzawa E, Nagai S, Sasaki K, Yano M, Sato T (2012) Identification of $q S O R 1$, a major rice QTL involved in soil-surface rooting in paddy fields. Theor Appl Genet 124:75-86

Uraguchi S, Fujiwara T (2012) Cadmium transport and tolerance in rice: perspectives for reducing grain cadmium accumulation. Rice 5:5

Vreugdenhil D, Aarts MGM, Koornneef M, Nelissen H, Ernst WHO (2004) Natural variation and QTL analysis for cationic mineral content in seeds of Arabidopsis thaliana. Plant, Cell Environ $27: 828-839$

Waters BM, Grusak MA (2008) Quantitative trait locus mapping for seed mineral concentrations in two Arabidopsis thaliana recombinant inbred populations. New Phytol 179:1033-1047

Weller JI, Song JZ, Heyen DW, Lewin HA, Ron M (1998) A new approach to the problem of multiple comparisons in the genetic dissection of complex traits. Genetics 150:1699-1706

Xiloyannis G, Celano G, Montanaro B, Dichio L, Sebastiani AM (2001) Water relations, calcium and potassium concentration in fruits and leaves during annual growth in mature kiwifruit plants. Acta Hort 564:129-134

Xu J-L, Yu S-B, Luo L-J, Zhong D-B, Mei H-W, Li Z-K (2004) Molecular dissection of the primary sink size and its related traits in rice. Plant Breed 123:43-50

Yamaji N, Ma JF (2009) A transporter at the node responsible for intervascular transfer of silicon in rice. Plant Cell 21:2878-2883

Zhang M (2010) Bayesian classification method for QTL mapping. In: Dey DK, Ghosh S, Mallick BK (eds) Bayesian modeling in bioinformatics. Chapman \& Hall/CRC, Boca Raton, pp 413-425

Zhang X, Zhang F, Mao D (1998) Effect of iron plaque outside roots on nutrient uptake by rice (Oryza sativa L.). Zinc uptake by Fedeficient rice. Plant Soil 202:33-39

Zhang X, Zhang F, Mao D (1999) Effect of iron plaque outside roots on nutrient uptake by rice (Oryza sativa L.). Phosphorus uptake. Plant Soil 209:187-192

Zhang Y, Lin X, Werner W (2004) Effects of aerobic conditions in the rhizosphere of rice on the dynamics and availability of phosphorus in flooded soil-a model experiment. J Plant Nutr Soil Sci 167:66-71

Zhang M, Montooth KL, Wells MT, Clark AG, Zhang D (2005) Mapping multiple quantitative trait loci by Bayesian classification. Genetics 169:2305-2318

Zhang M, Zhang D, Wells MT (2008) Variable selection with large $\mathrm{p}$ small $\mathrm{n}$ regression models: mapping QTL with epistasis. BMC Bioinform 9:251. doi:10.1186/1471-2105-9-251

Zhou XB, Shi WM, Zhang LH (2007) Iron plaque outside roots affects selenite uptake by rice seedlings (Oryza sativa L.) grown in solution culture. Plant Soil 290:17-28 